\title{
Progressive impairment of developing neuroendocrine cell lineages in the hypothalamus of mice lacking the Orthopedia gene
}

\author{
Dario Acampora, ${ }^{1}$ Maria Pia Postiglione, ${ }^{1}$ Virginia Avantaggiato, ${ }^{1}$ Maria Di Bonito, ${ }^{1}$ \\ Flora M. Vaccarino, ${ }^{2}$ Jacques Michaud, $^{3}$ and Antonio Simeone ${ }^{1,4}$ \\ ${ }^{1}$ International Institute of Genetics and Biophysics, Consiglio Nationale delle Ricerche (CNR), 80125 Naples, Italy; ${ }^{2}$ Yale \\ University, Child Study Center, New Haven, Connecticut 06520 USA; ${ }^{3}$ Service de Génétique Médicale, Hôpital \\ Sainte-Justine, Université de Montréal, Montréal (Québec) H3T 1C5, Canada
}

Development of the neuroendocrine hypothalamus is characterized by a precise series of morphogenetic milestones culminating in terminal differentiation of neurosecretory cell lineages. The homeobox-containing gene Orthopedia $(\mathrm{Otp})$ is expressed in neurons giving rise to the paraventricular $(\mathrm{PVN})$, supraoptic (SON), anterior periventricular (aPV), and arcuate (ARN) nuclei throughout their development. Homozygous Otp ${ }^{-/-}$ mice die soon after birth and display progressive impairment of crucial neuroendocrine developmental events such as reduced cell proliferation, abnormal cell migration, and failure in terminal differentiation of the parvocellular and magnocellular neurons of the aPV, PVN, SON, and ARN. Moreover, our data provide evidence that Otp and Sim1, a bHLH-PAS transcription factor that directs terminal differentiation of the PVN, SON, and aPV, act in parallel and are both required to maintain Brn2 expression which, in turn, is required for neuronal cell lineages secreting oxytocin (OT), arginine vasopressin (AVP), and corticotropin-releasing hormone (CRH).

[Key Words: Orthopedia; cell migration; cell proliferation; neuroendocrine hypothalamus; terminal differentiation]

Received August 5, 1999; revised version accepted September 21, 1999.

The hypothalamus and pituitary gland constitute the main axis of the neuroendocrine system and exhibit a remarkable coordination in temporal and spatial events regulating their development and differentiation (Simmons et al. 1990; Treier and Rosenfeld 1996). By integrating signals from the periphery and brain, this neuroendocrine system controls the synthesis and secretion of the hormones required for body growth, behavior, reproduction, and metabolism (Felig et al. 1987; Wilson and Foster 1992; Gass and Kaplan 1996; Treier and Rosenfeld 1996). The mature pituitary gland consists of five distinct cell types, each defined by the hormone(s) it produces. Thus, the cell types found in the anterior lobe are the thyrotropes, somatotropes, corticotropes, lactotropes, and gonadotropes that produce the thyroidstimulating hormone (TSH), growth hormone (GH), adrenocorticotropic hormone (ACTH), prolactin (PRL), follicle-stimulating hormone (FSH), and luteinizing hormone (LH), respectively (Swanson 1986, 1987; Felig et al. 1987; Wilson and Foster 1992; Gass and Kaplan

${ }^{4}$ Corresponding author.

E-MAIL simeone@iigbna.iigb.na.cnr.it; FAX 39/081/5936123 or 7257202.
1996). The neuroendocrine hypothalamus consists of two distinct neuronal populations; the magnocellular and parvocellular neurons (Swanson 1986, 1987; Sharp and Morgan 1996). The magnocellular neurons are grouped in the paraventricular (PVN) and supraoptic (SON) nuclei, project their axons to the posterior pituitary, and release oxytocin (OT) and arginine vasopressin (AVP). The parvocellular neurons project to the median eminence (ME), in which they release hypophysiotrophic hormones that are conveyed to the anterior pituitary by the hypophyseal-portal vascular system. The parvocellular neurons located in the PVN nucleus release corticotropin-releasing hormone (CRH) and thyrotropin-releasing hormone (TRH). Centered in ventrally contiguous cell groups in the anterior periventricular $(\mathrm{aPV})$ or the arcuate nuclei (ARN) of the hypothalamus are hypophysiotrophic neurons synthesizing somatostatin (SS) or growth-hormone-releasing hormone (GHRH), which impart the principal inhibitory and stimulatory regulation of $\mathrm{GH}$, respectively.

Parvocellular and magnocellular precursor neurons of the PVN and SON are generated in the mouse embryos between embryonic day 10 (E10) and E12 in the supraoptic/paraventricular (spv) area (Karim and Shoper 1980). A fraction of these neurons remains in a medial position 
to give rise to the PVN, whereas the residual portion migrates laterally to where they reach the final destination between E13.5 and E14.5 and form the SON (Karim and Sloper 1980). Between E13.5 and E14.5, neuroendocrine neurons start to synthesize hormones and this event defines the terminal differentiation of the neuroendocrine hypothalamus.

Genetic and molecular approaches have contributed remarkably toward identifying a number of genes functionally involved in the development of the neuroendocrine axis and most of them are homeobox-containing genes belonging to different gene families (Treier and Rosenfeld 1996). Members of the LIM, PTX, and OTX classes are required for proper transcriptional control of pituitary hormones and often exhibit cooperation between them and/or with specific cofactors (Bach et al. 1995, 1997; Lamonerie et al. 1996; Sheng et al. 1996; Szeto et al. 1996; Acampora et al. 1998).

A large family of POU domain factors has been cloned and classified (He et al. 1989). Members of this family, such as Pit1 and Brn2, have been studied extensively to clarify their role in the coordinate development of the hypothalamic-pituitary axis (Bodner et al. 1988; Ingraham et al. 1988; Li et al. 1990; Simmons et al. 1990; Nakai et al. 1995; Schonemann et al. 1995).

Recently, the bHLH-PAS transcription factor Sim 1 has been shown to play a crucial role in the development of parvocellular and magnocellular neurons of the PVN, SON, and aPV as well as in the maintenance of Brn2 expression (Michaud et al. 1998). Consequently, neuroendocrine impairments detected in $\mathrm{Brn}^{-/-}$mice (Nakai et al. 1995; Schonemann et al. 1995) are present also in mice lacking the Sim1 gene (Michaud et al. 1998). Finally, mice lacking the homeodomain factor Gsh-1 do not synthesize GHRH in the ARN (Li et al. 1996) indicating that Gsh-1 is required for proper development of a specific neuroendocrine cell lineage different from those requiring Sim1 and Brn2 (Li et al. 1996; Treier and Rosenfeld 1996).

Orthopedia (Otp) is a highly conserved homeodomaincontaining factor that is transcribed during murine embryonic development in a segment-like expression pattern including the anterior hypothalamus $(\mathrm{AH})$, spv, retrochiasmatic, and ventral tuberal areas (Simeone et al. 1994; Avantaggiato et al. 1995) that give rise to the aPV, PVN, SON, and ARN (Puelles and Rubenstein 1993; Rubenstein et al. 1994; Alvarez-Bolado et al. 1995).

Here, we report that in mice lacking Otp, aPV, PVN, and SON were absent, whereas ARN was impaired but present. Otp ${ }^{-/-}$mice failed to express CRH, TRH, AVP, OT, and SS, whereas they retained a normal expression of GHRH in the ARN. Furthermore, we provide evidence that Otp is required for multiple stage-specific cellular functions leading to the establishment of the neuroendocrine hypothalamus.

\section{Results}

Generation of Otp null mice

To decipher the Otp role in the development of the neu- roendocrine hypothalamus, Otp null mice were generated (Fig. 1A; see Materials and Methods). Homologous recombination events result in the deletion of part of the first exon and the entire second exon including the methionine and most of the homeodomain, and in the fusion of the lac Z coding sequence to the Otp 5'-untranslated region. HM-1 homologous recombinant ES cell clones were identified by PCR and confirmed by Southern blot analysis (Fig. 1B; Materials and Methods). Otp $p^{+/-}$ mice genotyped by allele-specific PCR reactions (Fig. 1C) were healthy and fertile, and their intercross yielded offspring in the expected mendelian ratio. Otp ${ }^{-/-}$pups died either at birth, or within the first two postnatal days (P1-P2) without apparent malformations. To assess the complete inactivation of the gene, the absence of the OTP protein was confirmed by a Western blot assay on E13.5 Otp ${ }^{-/-}$embryonic extracts with an anti-OTP polyclonal antibody (Fig. 1D).

To verify whether the lacZ expression was correctly driven by Otp-transcription control elements, transcripts from the normal (probe b in Fig. 1A) and mutated (probe c in Fig. 1A) alleles were compared with each other. In particular, in heterozygotes at E13.5 (Fig. 1G,H), E15.5 (Fig. 1I,J), and P1 (Fig. 1K,L), the expression patterns of the normal and mutated alleles were totally overlapping, thus indicating that lac $Z$ was a reliable marker to follow Otp-expressing cells in $O t p^{+/-}$and $O t p^{-/-}$mutants. Similarly, at E10 and E12.5, the $\beta$-galactosidase ( $\beta$-gal) staining (Fig. 1E,F) was very similar or identical to the Otp RNA distribution revealed by whole-mount in situ hybridization experiments (data not shown). On this basis, although all the analyzed $\mathrm{Otp}^{+/-}$brains were hybridized with both the allele-specific probes, we have chosen here to show only lacZ expression.

\section{Anatomo-histological and molecular abnormalities in $\mathrm{Otp}^{-/-}$mice}

Anatomo-histological analysis of $\mathrm{Otp}^{-/-}$brains at postnatal day (P1) showed evident abnormalities in the hypothalamus. Nissl staining of histological sections revealed that as compared with $\mathrm{Otp}^{+/-}$(Fig. 2A,C,E,G), in Otp ${ }^{-/-}$brains, the presumptive PVN and SON showed hypocellularity and absence of proper morphological fea-

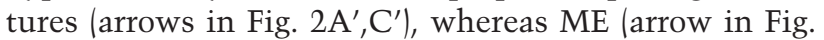
$2 \mathrm{E}^{\prime}$ ) and the posterior lobe of the pituitary gland (Fig. 2G') were extremely hypoplastic. Surrounding structures such as the suprachiasmatic nucleus (SCN) and the zona incerta (ZI) appeared morphologically normal (Fig. 2A'; data not shown). To reinforce these observations, in situ detection of calbindin D28K (calb) by a polyclonal antibody $(\alpha$-calb) was determined. $\alpha$-calb stained restricted neuronal populations including neurons of the SON, PVN (Fig. 2B,D), as well as projections from the PVN and aPV to the ME (Fig. 2F; Enderlin et al. 1987; Nakai et al. 1995). According to the morphological analysis, calb immunoreactivity resulted essentially abolished in the presumptive SON, PVN, and ME of Otp ${ }^{-/-}$brains (Fig. $\left.2 \mathrm{~B}^{\prime}, \mathrm{D}^{\prime}, \mathrm{F}^{\prime}\right)$. Noteworthy, in Otp $\mathrm{p}^{-/-}$brains, the proliferat- 

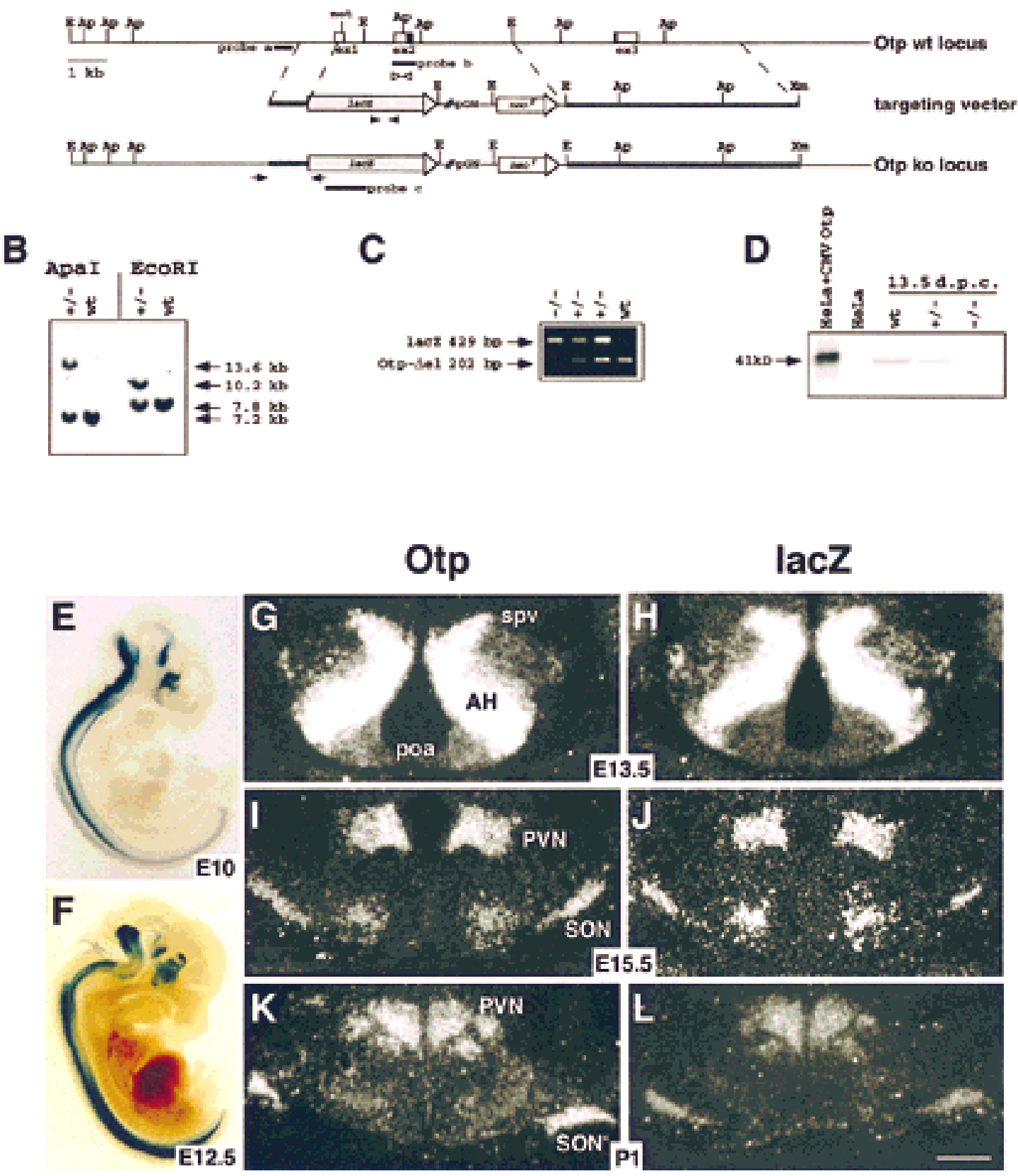

Figure 1. Targeted replacement of Otp with the lacZ gene. (A) Schematic representation of the wild-type Otp allele, targeting vector, and recombined allele. E, Ap and Xm stand for EcoRI, ApaI, and XmnI. The locations of probes a, b, and c used for Southern blot analyses (probes a and c) and in situ hybridizations (probes b and c) are indicated. The arrows in the third line indicate the position of the primers used to identify homologous recombinant clones. (B) Southern blot analysis of one targeted ES cell line and wild-type HM-1 ES cells showing expected hybridization pattern of ApaI and EcoRI-digested genomic DNA samples with probe a $(A)$. Only the 13.6-kb band with ApaI and the 10.2-kb band with EcoRI were detected with the lacZ internal probe c (data not shown). (C) Genotyping of littermates from the intercross of heterozygotes by a PCR reaction amplifying fragments specific for the deleted region of Otp (Otp $\Delta e 1)$ (202 bp) and lacZ (429 bp), with the primers indicated as open and filled arrowheads, respectively. (D) Western blot analysis of the OTP protein in transfected HeLa cells and embryonic extracts. $(E-L) \beta$-gal staining of Otp ${ }^{+/-}$embryos at E10 (E) and E12.5 (F) and in situ hybridization on adjacent sections of $\mathrm{Otp}^{+/-}$brains at E13.5 $(G, H), \mathrm{E} 15.5(I, J)$, and P1 $(K, L)$ with allele-specific probes (probes $\mathrm{b}$ and $\mathrm{c}$ in $A$ ) revealing no difference between the wild-type and the targeted locus. (spv) Supraoptic/paraventricular area; (AH) anterior hypothalamus; (PVN) paraventricular nucleus; (poa) anterior preoptic area; (SON) supraoptic nucleus. For sections in $G-L$, scale bar corresponds to $50 \mu \mathrm{m}(L)$. 


\section{Otp +/- Otp $\%$}

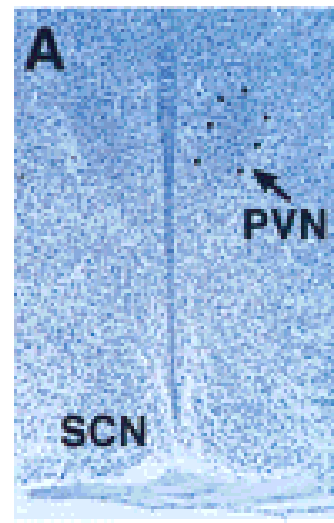

\section{B}
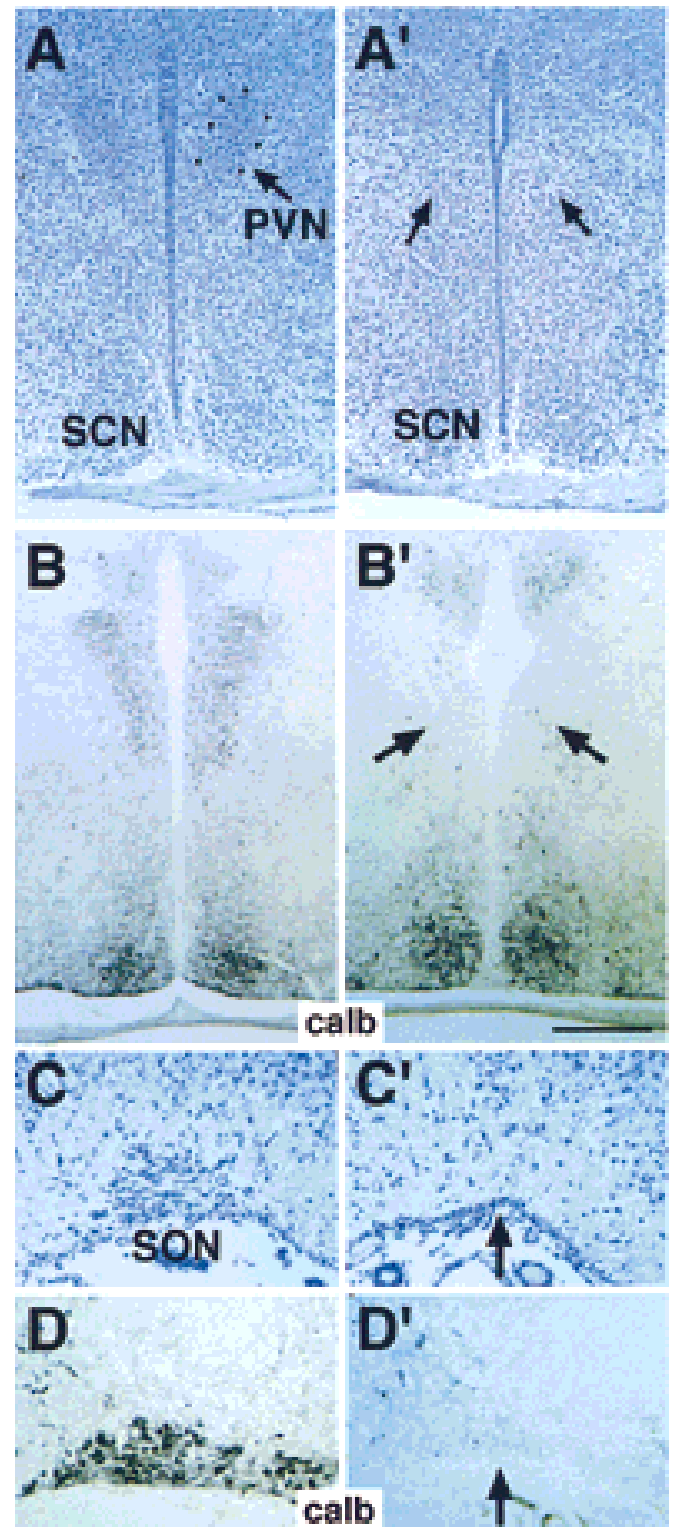

Otp +/-
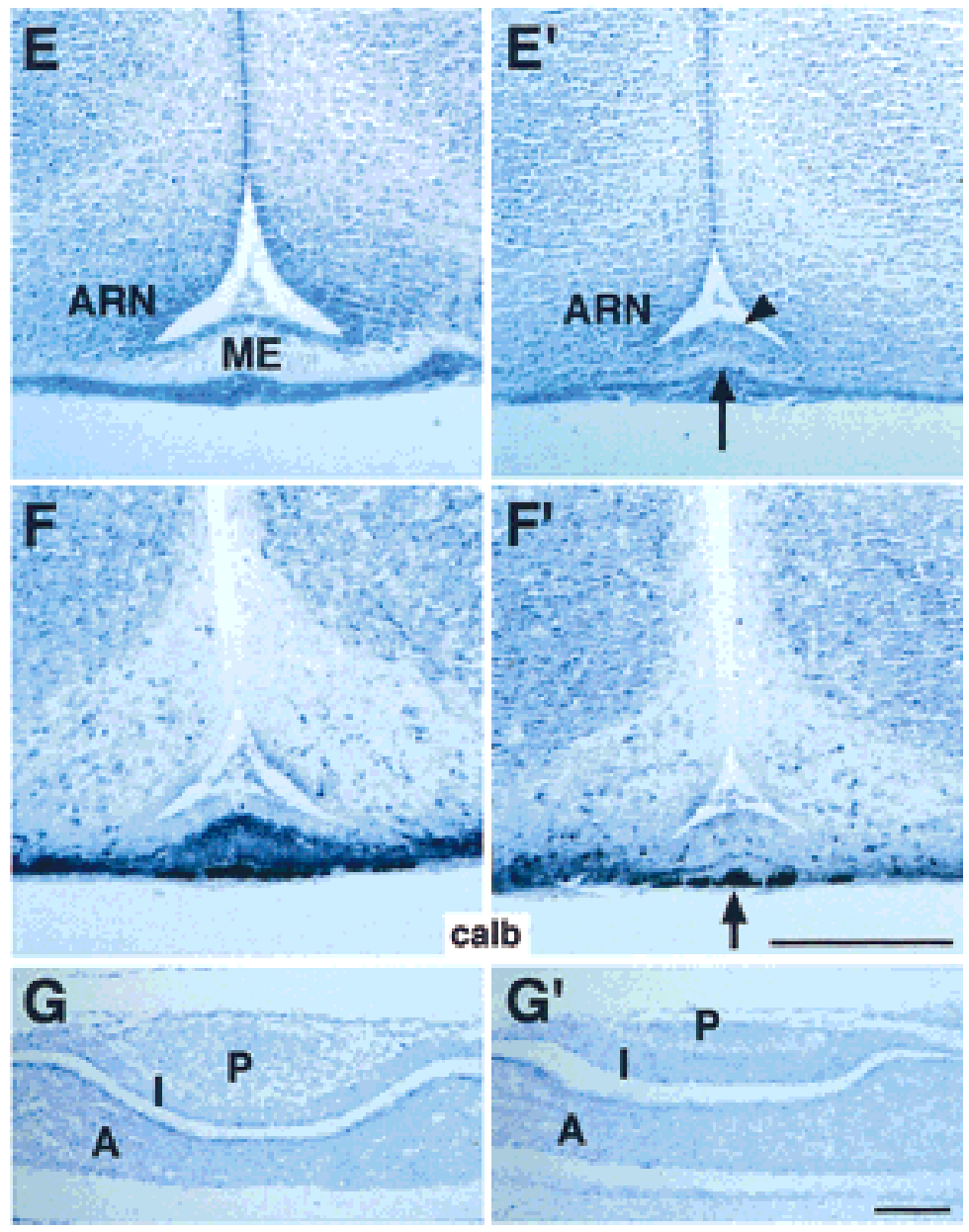

Figure 2. Abnormalities in the hypothalamus and pituitary of Otp ${ }^{-/-}$mice. $\left(A-F^{\prime}\right)$ Nissl staining $\left(A, A^{\prime}, C, C^{\prime}, E, E^{\prime}\right)$ and calb-positive cells $\left(B, B^{\prime}, D, D^{\prime}, F, F^{\prime}\right)$ in sections through the $\operatorname{PVN}\left(A, B^{\prime}\right), \operatorname{SON}\left(C, D^{\prime}\right)$, and $\mathrm{ME}\left(E, F^{\prime}\right)$ of $O t p^{+/-}(A-F)$ and Otp ${ }^{-1-}\left(A^{\prime}-F^{\prime}\right)$ newborns. Arrows in $A^{\prime}-D^{\prime}$ indicate the lack of the PVN $\left(A^{\prime}\right)$ and SON $\left(C^{\prime}\right)$ confirmed by the absence of calb-positive cells $\left(B^{\prime}, D^{\prime}\right)$. The arrows in $E^{\prime}$ and $F^{\prime}$ point to the heavy reduction in thickness of the $M E\left(E^{\prime}\right)$ that results poorly stained with $\alpha$-calb antibody $\left(F^{\prime}\right)$. Note that the neuroepithelium adjacent to the presumptive ME results in increased thickness (arrowhead in $E^{\prime}$ ). $\left(G, G^{\prime}\right)$ As compared with $O t p^{+/-}(G)$, the posterior lobe of the pituitary gland is strongly hypoplastic in Otp $p^{-/-}$mice $\left(G^{\prime}\right)$. Abbreviations as in the previous figure; ( $\mathrm{ME}$ ) median eminence; $(\mathrm{SCN})$ suprachiamastic nucleus; (ARN) arcuate nucleus; (A) I, P anterior, intermediate, and posterior lobes of the pituitary. Scale bars, $50 \mu \mathrm{m}$. Scale bar in $B^{\prime}$ refers to $A$ and $B^{\prime}$; scale bar in $F^{\prime}$ to $C-F^{\prime}$, and scale bar in $G^{\prime}$ to $G-G^{\prime}$.

ing neuroepithelium adjacent to the presumptive $\mathrm{ME}$ was found to be increased in thickness (arrowhead in Fig. $\left.2 E^{\prime}\right)$.

To further characterize the defects in the neuroendocrine hypothalamus, we wondered whether lac $Z$ expression was affected. In $\mathrm{Otp}^{+/-}$brains, lacZ is expressed all along the PVN (Fig. 3A-C), in the aPV (Fig. 3A), the anterior hypothalamic area (AH) (Fig. 3A), the SON (Fig. 3B), the ARN (Fig. 3D), a narrow domain of cells adjacent to the ARN (arrowheads in Fig. 3D), and the premam- millary area (pMA) (Fig. 3D). In Otp $p^{-/-}$brains, an evident reduction in the number and position of cells expressing lacZ was observed (Fig. 3A'-D'). lacZ-positive cells were detected in a territory that normally did not express $O t p$ $\left(\right.$ Fig. $\left.3 \mathrm{~A}^{\prime}-\mathrm{C}^{\prime}\right)$, and no transcripts were found in the presumptive area corresponding to the $\mathrm{aPV}, \mathrm{PVN}$, and SON (Fig. $\left.3 \mathrm{~A}^{\prime}-\mathrm{C}^{\prime}\right)$. In contrast, lacZ expression in the ARN was retained, even though in an apparently reduced number of cells (Fig. 3D'). These data, therefore, suggest that differentiation, proliferation, and migration of 
Otp +/-
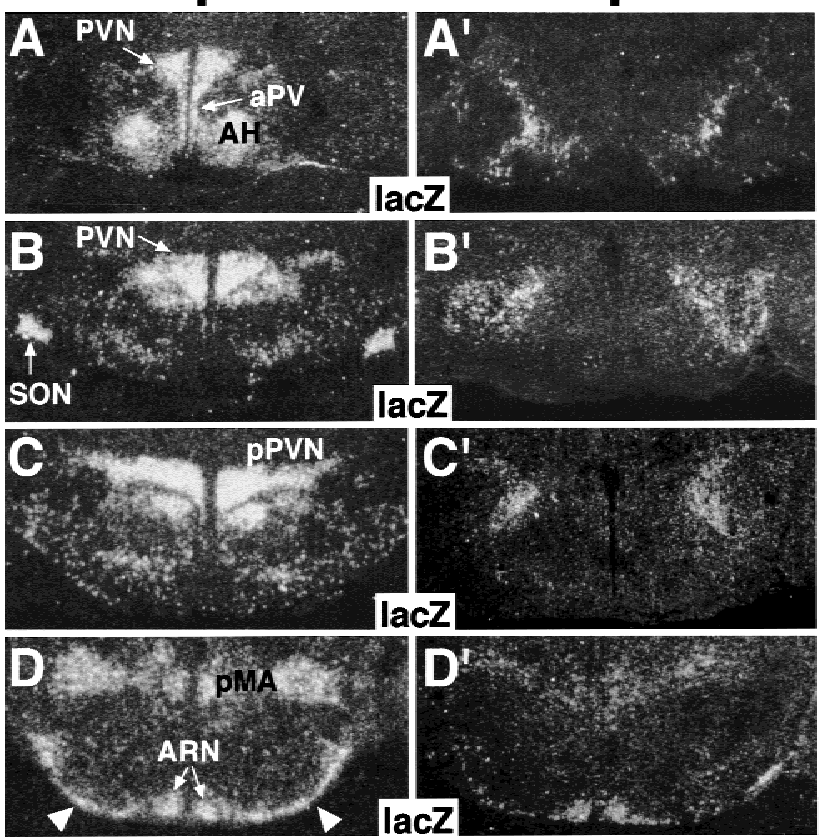

Figure 3. Abnormal lacZ expression and lack of neuroendocrine hormones in $O t p^{-/-}$brain. $\left(A-C^{\prime}\right)$ Coronal sections of $O t p^{+/-}(A-C)$ and $O t p^{-/-}\left(A^{\prime}-C^{\prime}\right)$ brains at P1 showing that lacZ is expressed in $\mathrm{Otp}^{+/-}$brain all along the PVN $(A-C)$, aPV $(A)$, $\mathrm{AH}(A)$, and SON $(B)$, whereas in $O t p^{-1-}$, brain, lacZ transcripts disappear from the presumptive areas corresponding to the PVN $\left(A^{\prime}-C^{\prime}\right)$, aPV $\left(A^{\prime}\right), \mathrm{AH}\left(A^{\prime}\right)$, and SON $\left(B^{\prime}\right)$ and are detected in a misplaced domain that normally never expresses Otp $\left(A^{\prime}-C^{\prime}\right)$. $\left(D, D^{\prime}\right)$ In sections through the ARN of $\operatorname{Otp}^{+/-}(D)$ and $O t p^{-/-}\left(D^{\prime}\right)$ brains, lacZ is expressed in the ARN, in a narrow domain adjacent to the ARN (arrowheads) and in a region possibly including the premammillary nucleus. Note the remarkable reduction in lacZ expression in $O t p^{-/-}$brains. $\left(E-K^{\prime}\right)$ In Otp $p^{+/-}$brain $(E-K)$, TRH $(E)$ is detected in the PVN and in scattered neurons, CRH $(F)$ in the PVN, AVP $(G)$ in the PVN, SON, and SCN, OT $(H)$ in the PVN and SON, SS $(I, J)$ in numerous areas and among them in the aPV $(I)$ and ARN $(J)$ and GHRH in the ARN $(K)$, whereas in Otp ${ }^{-/-}$brain $\left(E^{\prime}-K^{\prime}\right)$, TRH $\left(E^{\prime}\right), \mathrm{CRH}\left(F^{\prime}\right), \operatorname{AVP}\left(G^{\prime}\right)$, and OT $\left(H^{\prime}\right)$ are undetectable in the PVN and SON, SS is not transcribed in the aPV $\left(I^{\prime}\right)$ and ARN $\left(J^{\prime}\right)$, whereas GHRH $\left(K^{\prime}\right)$ appears unaffected. Also note that in Otp ${ }^{-/-}$mice, TRH expression totally disappears in the hypothalamus; AVP expression is retained in the SCN (G'), and SS-positive neurons are not identified in the area surrounding the ARN ( $\left.f^{\prime}\right)$. Abbreviations as in the previous figures; (aPV) anterior periventricular nucleus; (pMA) premammillary nucleus. Scale bar, $50 \mu \mathrm{m}$.

Otp ${ }^{-/-}$- expressing cells might be heavily perturbed. In this context, we wondered whether the ability to transcribe OT, AVP, TRH, CRH, GHRH, and SS was still retained. As compared with $O t p^{+/-}$(Fig. 3E-K), in Otp ${ }^{-/-}$ (Fig. $3 \mathrm{E}^{\prime}-\mathrm{K}^{\prime}$ ) brains, TRH, CRH, OT, and AVP were not expressed in the PVN (TRH and CRH) (Fig. $3 \mathrm{E}^{\prime}, \mathrm{F}^{\prime}$ ) or in the PVN and SON (AVP and OT) (Fig. $\left.3 \mathrm{G}^{\prime}, \mathrm{H}^{\prime}\right)$; SS was

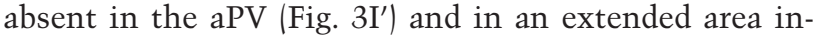
cluding the ARN and surrounding territory (Fig. 3 $\mathrm{J}^{\prime}$ ), whereas GHRH was correctly transcribed (Fig. 3K'). Moreover, it is noteworthy that TRH-positive neurons totally disappeared in Otp ${ }^{-/-}$brains (Fig. 3E'; see below), and AVP transcription was not affected in the SCN, in which Otp was not expressed (Fig. 3G'). Noteworthy, in some (two of seven) of the Otp ${ }^{-/-}$brains analyzed, the AVP expression in the SCN appeared increased.
Therefore, these findings prove that Otp codes for a critical function required for the correct development of the neurosecretory system and indicate that Otp-expressing cells that are normally committed to giving rise to neuroendocrine nuclei appear reduced in number and placed in an abnormal position.

\section{Failure in terminal differentiation of the neuroendocrine hypothalamus in $\mathrm{Otp}^{-/-}$embryos}

Terminal differentiation of major neuroendocrine nuclei was marked by the expression of hormones between E13.5 and E14.5. Therefore, we studied whether the onset of hormone expression was correctly established at with $\mathrm{Otp}^{+/-}$embryos (Fig. 4A-M), the expression of TRH E13.5 (data not shown) and E14.5 (Fig. 4). As compared 


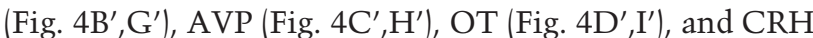

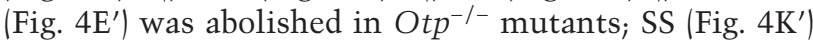
transcripts were not detected in the ARN or in the adjacent area, whereas the GHRH was expressed normally (Fig. 4L'). The same result was obtained at E13.5 for the hormones already expressed at this stage (data not shown). Thus, in Otp ${ }^{-/-}$embryos, neuropeptide expression failed to be established in the PVN and SON, whereas it resulted partially impaired in the ARN.

To correlate lack of hormones to the Otp expression domain, the distribution of $l a c Z$ trancripts was investigated. In $O t p^{+/-}$embryos, lac $Z$ was coexpressed with the hormones (Fig. 4A,F,J) and interestingly, at the level of the posterior PVN (pPVN), lacZ (Fig. 4F) was detected in two streams of cells deriving from it and likely migrating in a latero-ventral direction to form the posterior SON and expressing AVP and OT (Fig. 4H,I), or in a more medio-ventral direction and expressing TRH (Fig. 4G). In $O t p^{-/-}$, at the level of the preoptic area (poa) lacZ transcripts were detected in the $\mathrm{AH}$, but not in the presumptive PVN (arrow in Fig. 4A'), whereas they were found at the level of the presumptive pPVN (Fig. 4F'). Nevertheless, in this area, OT/AVP and TRH-positive neurons were not identified and an abnormal lac $Z$ expression was detected (Fig. 4F'). At the level of ARN and adjacent re- gions, a moderate reduction of both lacZ expression and calb-positive cells was observed (Fig. 4J', $\mathrm{M}^{\prime}$ ).

\section{Early development of hypothalamic neuroendocrine precursor cells and Otp expression in Sim 1 mutants}

To study how and when the abnormal phenotype was generated, a detailed analysis was performed from E10.5 to E14.5. As mentioned previously, Brn2 and Sim1 genes are expressed and required for the correct development of aPV, PVN, and SON (Nakai et al. 1995; Schonemann et al. 1995; Michaud et al. 1998). In addition, calb is an early marker of most of the neuronal cells committed to form PVN and SON, even before the onset of the hormone transcription (Nakai et al. 1995). For these reasons, their expression patterns were analyzed and compared with that of lacZ in adjacent sections. The first abnormality was detected at E10.3, when a smaller domain of $\beta$-gal staining was observed in Otp ${ }^{-/-}$embryos (data not shown). At E11.5, in Otp ${ }^{-/-}$embryos, the lacZ and Sim1 domains were narrowed in both the spv and AH primordia and Brn2 expression was slightly toned down in the postmitotic areas in which it was coexpressed with lacZ (data not shown).

At E 12.5 in Otp ${ }^{-/-}$embryos, the hypothalamic im-
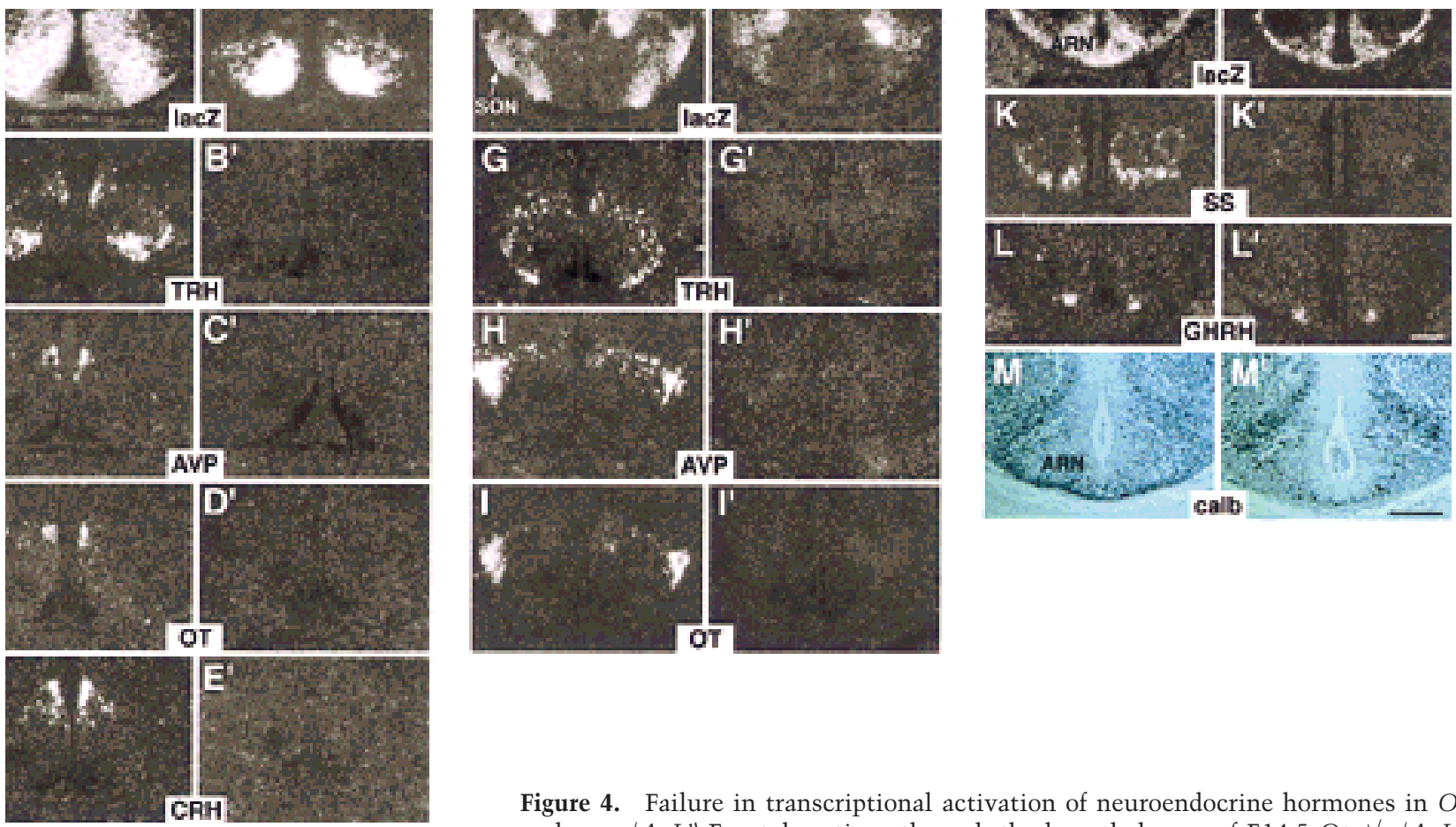

Figure 4. Failure in transcriptional activation of neuroendocrine hormones in Otp $\mathrm{Tp}^{-/-}$ embryos. $\left(A-L^{\prime}\right)$ Frontal sections through the hypothalamus of E14.5 Otp ${ }^{+/-}(A-L)$ and $O t p^{-/-}\left(A^{\prime}-L^{\prime}\right)$ embryos showing that at the level of the poa area $\left(A-E^{\prime}\right)$ lac $Z$ transcripts disappear from the presumptive PVN primordium (arrow in $\left.A^{\prime}\right)$ and TRH $\left(B^{\prime}\right), \operatorname{AVP}\left(C^{\prime}\right)$, OT $\left(D^{\prime}\right)$, and CRH $\left(E^{\prime}\right)$ hormone transcripts are not detected; at the level of the pPVN $\left(F-I^{\prime}\right)$ lacZ is abnormally transcribed $\left(F^{\prime}\right)$ and no expression appears for the TRH $\left(G^{\prime}\right)$, AVP $\left(H^{\prime}\right)$, and OT $\left(I^{\prime}\right)$; and at the level of the ARN $\left(J-L^{\prime}\right)$ no macroscopic abnormalities are detected in the distribution of $\operatorname{lacZ}\left(J^{\prime}\right)$ and GHRH $\left(L^{\prime}\right)$ transcripts, whereas SS-positive neurons disappear $\left(K^{\prime}\right) .\left(M, M^{\prime}\right)$ As compared with $\operatorname{Otp}^{+/-}(M)$, a considerable reduction in the number of calb-positive cells is observed in the ARN and surrounding areas of $O t p^{-/-}$embryos $\left(M^{\prime}\right)$. Abbreviations as the previous figures. Scale bars, $50 \mu \mathrm{m}$. Scale bar in $L^{\prime}$ refers to dark fields, and in $M^{\prime}$ to $M$, and $M^{\prime}$. 
pairments began to be evident. In Otp ${ }^{+/-}$embryos, Brn2 expression (arrow in Fig. 5B,E) overlapped with that of $1 a c Z$ in the spv primordium at the level of both the poa and posterior preoptic (pop) areas (arrow in Fig. 5A,D), and numerous migrating calb-positive cells were identified within the lac $Z$ domain (Fig. 5C,F). Interestingly, in Otp ${ }^{-1-}$ embryos, Brn2 was not transcribed in the spv (arrow in Fig. $5 \mathrm{~B}^{\prime}, \mathrm{E}^{\prime}$ ), and the number of calb-positive cells resulted markedly reduced (Fig. $\left.5 \mathrm{C}^{\prime}, \mathrm{F}^{\prime}\right)$. This latter observation is in agreement with the lack of Brn2 expression, because a very similar reduction in the number of calb-positive cells has been already reported in mice lacking Brn2 (Nakai et al. 1995).

In comparison with $\mathrm{Otp}^{+/-}$at E13.5 (Fig. 6A-H), in Otp ${ }^{-/-}$embryos at the level of the poa region, lacZ and Sim1 transcripts were not uniformly distributed in the spv and $\mathrm{AH}\left(\right.$ Fig. $\left.6 \mathrm{~A}^{\prime}, \mathrm{C}^{\prime}\right)$ and in sections crossing the pop area were abolished in the early presumptive SON area (arrow in Fig. 6E', $\mathrm{G}^{\prime}$ ) and heavily reduced in the spv (arrowheads in Fig. $6 \mathrm{E}^{\prime}, \mathrm{G}^{\prime}$ ), whereas they were apparently unaffected in the $\mathrm{AH}$ (Fig. $6 \mathrm{E}^{\prime}, \mathrm{G}^{\prime}$ ). Brn2 continued to be expressed only in the periventricular neuroepithelium (Fig. $6 \mathrm{~B}^{\prime}, \mathrm{F}^{\prime}$ ) and very few and disorganized calb-positive cells were still detected in restricted regions coexpressing lacZ and Sim1 (Fig. 6D', and circled area in $\mathrm{H}^{\prime}$ ). No calb-positive cells were identified in the presumptive SON region (arrow in Fig. $6 \mathrm{H}^{\prime}$ ). Finally, at E14.5, the major abnormalities described at P1 were evident. As compared with Otp $p^{+/-}$(Fig. 6I-P), in Otp ${ }^{-/-}$embryos at the level of the poa region, the expression of lac $Z$ and Sim1 disappeared from the presumptive PVN region (arrow in Fig. $\left.6 \mathrm{I}^{\prime}, \mathrm{K}^{\prime}\right)$. Brn2 expression and calb-positive cells were undetectable in the PVN (Fig. 6J and arrow in $\mathrm{L}^{\prime}$ ).

At the level of the presumptive pPVN, lac Z and $\operatorname{Sim} 1$ were cotranscribed in an abnormal domain (Fig. 6 $\mathrm{M}^{\prime}, \mathrm{O}^{\prime}$ ); Brn2 was not expressed (Fig. $6 \mathrm{~N}^{\prime}$ ), and a few calb-positive

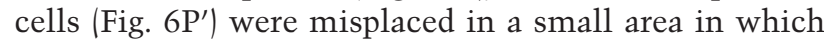
lac $Z$ and $\operatorname{Sim} 1$ were transcribed (circled area in Fig. 6P' and arrowhead in $\left.\mathrm{M}^{\prime}, \mathrm{O}^{\prime}\right)$. To investigate whether Otp might be downstream of Sim1, Otp expression was studied in Sim $1^{-1-}$ embryos. At E12.5, as compared with Sim $1^{+/-}$(Fig. 7A, $\mathrm{A}^{\prime}$ ), in Sim $1^{-1-}$ embryos, Otp (Fig. 7B') was stably transcribed in the territory expressing the Sim1 null alleles (Fig. 7B), thus indicating that the Otp expression does not require the SIM1 gene product to be maintained.

In summary, these data suggest that (1) between E10 and E12, reduced proliferating activity and/or increased cell death might be responsible for the reduction in the extent of lacZ and Sim1 domains; (2) subsequently, between E13 and E15, at the level of the poa region, the PVN cells became disorganized, and then at E14.5, probably died as revealed by the disappearence of four different markers (1acZ, Brn2, Sim1, and calb); (3) at the level of the pop area, at least a fraction of lacZ-positive cells destined to form the pPVN and two distinct cell populations normally secreting AVP/OT or TRH (Fig. 4F-I) still survived, but failed to both properly differentiate

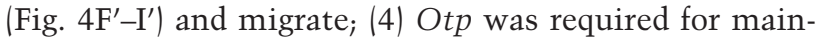
tenance of Brn2 expression in the spv, whereas it was not required to control Sim1 transcription; (5) Sim1 is not required for Otp expression in $\operatorname{Sim} 1^{-/-}$mutants.

\section{Apoptosis and cell proliferation in $\mathrm{Otp}^{-/-}$embryos}

On the basis of previous considerations, apoptosis and cell proliferation were studied in Otp mutants and Otp expression was analyzed in $\operatorname{Sim}^{-/-}$embryos. Apoptosis was investigated at E10.5, E11.5, E12.5, E13.5, E14.5, E15.5, and P1. Three mutants for each stage were analyzed. In situ detection of apoptotic cells by the TUNEL method (Gavrieli et al. 1992) revealed no significant difference between $O t p^{+/-}$and Otp ${ }^{-/-}$embryos at all the stages analyzed in both the areas expressing lacZ or not (data not shown), thus indicating that even though Ot $p^{-/-}$embryos were affected by increased cell death, this was not due to apoptosis. The gradual reduction of the $1 a c Z$ expression domain observed from E13 onward

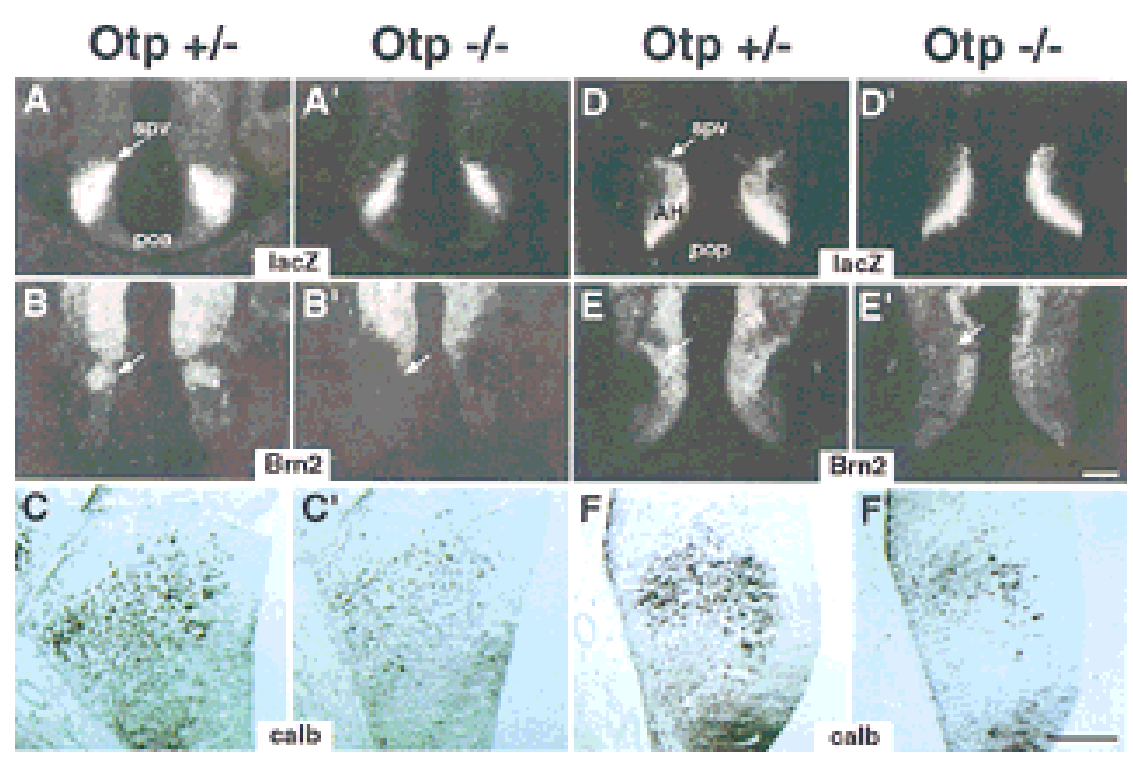

Figure 5. Abnormalities in Otp $p^{-/-}$embryos at E12.5. $\left(A-F^{\prime}\right) \operatorname{Otp}^{+/-}(A-F)$ and Otp ${ }^{-1-}\left(A^{\prime}-F^{\prime}\right)$ embryos hybridized with the indicated $\operatorname{lac} Z\left(A, A^{\prime}, D, D^{\prime}\right)$ and Brn2 $\left(B, B^{\prime}, E, E^{\prime}\right)$ probes or processed for detecting calb-positive cells $\left(C, C^{\prime}, F, F^{\prime}\right)$ in sections adjacent to those hybridized with radioactive probes and photographed at a higher magnification. Note that Otp ${ }^{-/-}$ embryos show narrowed expression domains of lacZ $\left(A^{\prime}, D^{\prime}\right)$; lack of Brn2 transcripts in the spv (arrow in $B^{\prime}, E^{\prime}$ ); and, finally, a remarkable reduction in the number of calb-positive cells $\left(C^{\prime}, F^{\prime}\right)$. Abbreviations as in the previous figures; in $C, C^{\prime}, F, F^{\prime}$ the third ventricle is at right. Scale bars, $50 \mu \mathrm{m}$. Scale bar in $E^{\prime}$ refers to dark fields and in $F^{\prime}$ to bright fields. 
Figure 6. Abnormalities in Otp $\mathrm{P}^{-/-} \mathrm{em}$ bryos at E13.5 and E14.5. $\left(A-P^{\prime}\right)$ Adjacent frontal sections of $\mathrm{Otp}^{+/-}(A-P)$ and $\mathrm{Otp}^{-/-}$ $\left(A^{\prime}-P^{\prime}\right)$ embryos at E13.5 $\left(A-H^{\prime}\right)$ and E14.5 $\left(I-P^{\prime}\right)$ are hybridized with the indicated lacZ, Brn2, and Sim1 or stained for detecting calb-positive cells. At E13.5 in sections through the poa area of Otp $p^{-/}$embryos, $\operatorname{lac} Z\left(A^{\prime}\right)$ and $\operatorname{Sim} 1\left(C^{\prime}\right)$ transcripts are disorganized and poorly condensed in the spv and in sections through the pop area; the $1 a c Z$ and $\operatorname{Sim} 1$ expression disappears from the presumptive SON (cf. arrows in $E, G$ with arrows in $\left.E^{\prime}, G^{\prime}\right)$ and is heavily affected in the spv region (cf. arrowheads in $E, G$ with arrowheads in $\left.E^{\prime}, G^{\prime}\right)$. At E14.5 in sections through the poa area, lac $Z$ and Sim1 expression is not detected in the PVN primordium (arrow in $I^{\prime}, K^{\prime}$ ) and at the level of pPVN, a fraction of migrating lacZ- $\left(M^{\prime}\right)$ and Sim1- $\left(O^{\prime}\right)$ positive cells is still identified. In E13.5 and E14.5 Otp ${ }^{-/-}$ embryos, only sporadic calb-positive cells are identified in the spv/PVN primordium (cf. $D$ with $D^{\prime}$ and arrow in $L$ with arrow in $L^{\prime}$ ) and in the presumptive SON (cf. arrow in $H, P$ with arrow in $H^{\prime}, P^{\prime}$, respectively). Note that the circled group of calb-positive cells $\left(P^{\prime}\right)$ that is coincident with the lac $Z$ and Sim 1 expression (arrowhead in $\left.M^{\prime}, O^{\prime}\right)$ may, possibly, correspond to residual cells that would be committed to migrate and form the SON. Finally, Brn2 expression in the spv, PVN, SON, and pPVN of $O t p^{+/-}$embryos $(B, F, J, N)$ is undetectable in Otp ${ }^{-/-}$mutants $\left(B^{\prime}, F^{\prime}, I^{\prime}, N^{\prime}\right)$. Note that calb-staining sections $\left(D, D^{\prime}\right.$, $\left.H, H^{\prime}, L, L^{\prime}, P, P^{\prime}\right)$ are adjacent to those hybridized with radioactive probes, but are photographed at a higher magnification. Abbreviations as in the previous figures and in $L, L^{\prime}, P, P^{\prime}$, the third ventricle is at right. Scale bars, $50 \mu \mathrm{m}$. Scale bar in $G^{\prime}$ refers to $A-C^{\prime}$ and $E-G^{\prime}$; scale bar in $O^{\prime}$ to $I-K^{\prime}$ and $M-O^{\prime}$; scale bar in $H^{\prime}$ to $D, D^{\prime}, H, H^{\prime}$; scale bar in $P^{\prime}$ to $L, L^{\prime}, P, P^{\prime}$.

\section{Otp +/- Otp $-/-$}
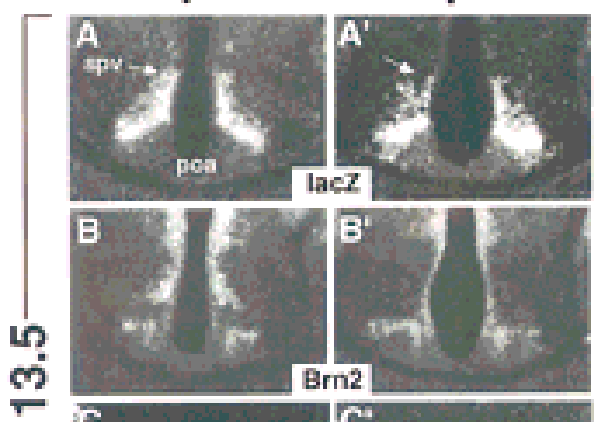

U1
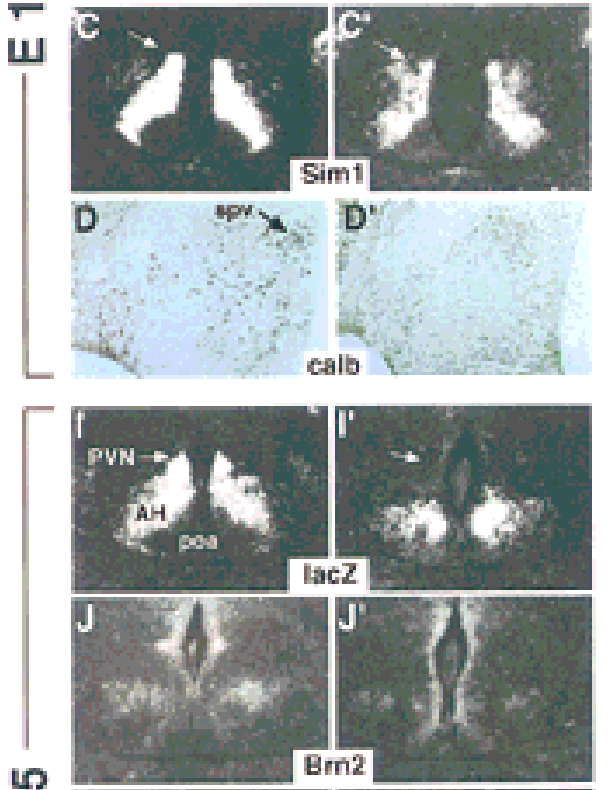

I?
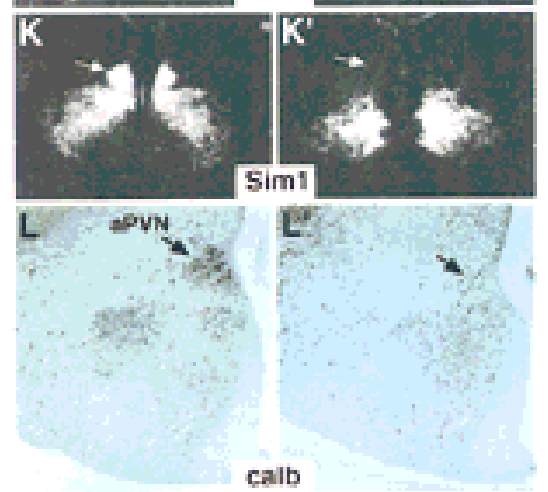

Otp +/- Otp - -
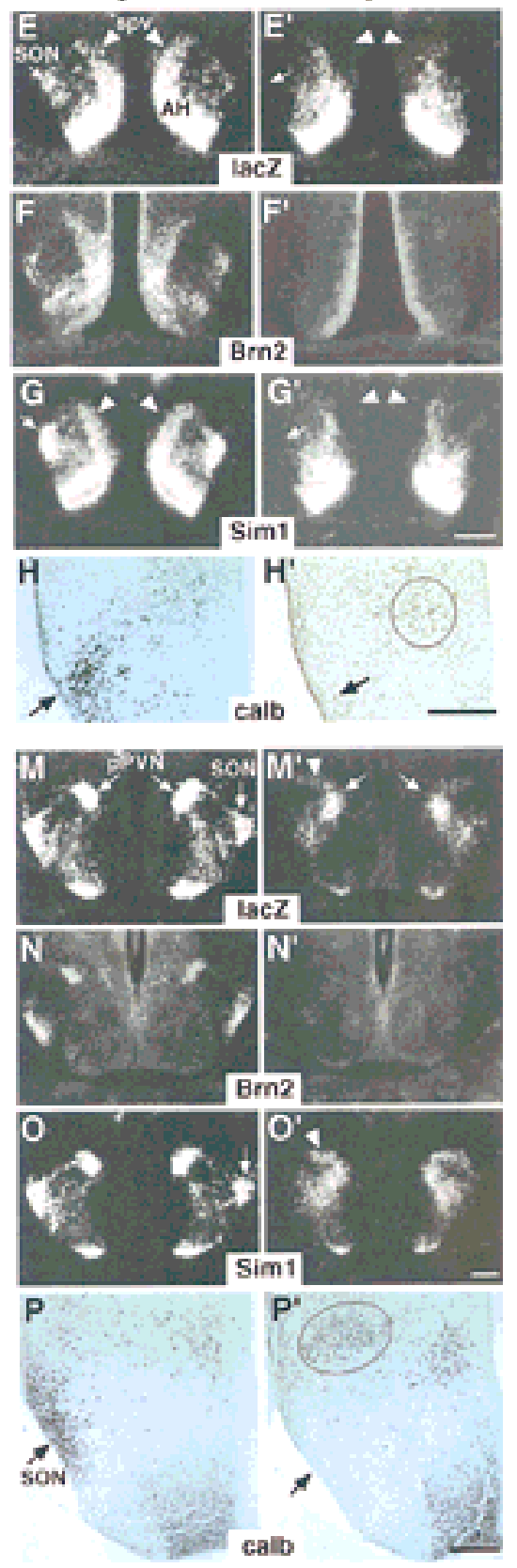

led us to strongly suspect that survival of a cospicuous number of lacZ-positive cells was compromised during mid-late gestation.

Cell proliferation was investigated by both a short pulse or a longer exposure to bromodeoxyuridine (BrdU) and subsequent comparison between BrdU- and lacZpositive cells in Otp $\mathrm{p}^{+/-}$and Otp $\mathrm{p}^{-/-}$embryos. Because a thinner lacZ domain was already evident in E10.5 Otp ${ }^{-/-}$ embryos (Fig. 7F; data not shown) and neuronal precursors of SON and PVN were generated massively between E10 and E12 (Karim and Sloper 1980), pregnant mice at E10.3, E11.3, and E12.5 were injected with BrdU and sacrificed after $1 \mathrm{hr}$. Within the proliferating neuroepithelium, lacZ was transcribed only in those neurons that were close to the mantle zone (Fig. 7C-H) and BrdUpositive cells were detected approximately in the same number in Otp $\mathrm{p}^{+/-}$and Otp $\mathrm{p}^{-/-}$embryos (Fig. 7, cf. $\mathrm{C}^{\prime}, \mathrm{D}^{\prime}, \mathrm{E}^{\prime}$ with $\left.\mathrm{F}^{\prime}, \mathrm{G}^{\prime}, \mathrm{H}^{\prime}\right)$, thus indicating that abnormality in proliferative activity measured in $1 \mathrm{hr}$ of exposure to BrdU was not evident in Otp ${ }^{-/-}$embryos. Nevertheless, to investigate the fate and the number of proliferating neuroblasts detected over a longer temporal window, embryos were injected with BrdU at E11.3 and sacrificed at E12.5. The number of BrdU-positive cells amassed within the lacZ domain at E12.5 was remarkably decreased in Otp $p^{-/-}$embryos and their position was abnormal (Fig. 7, cf. I,I' with $\left.\mathrm{K}, \mathrm{K}^{\prime}\right)$. Moreover, when BrdU was injected at E10.3 and the embryos analyzed at E12.5, a decrease in 

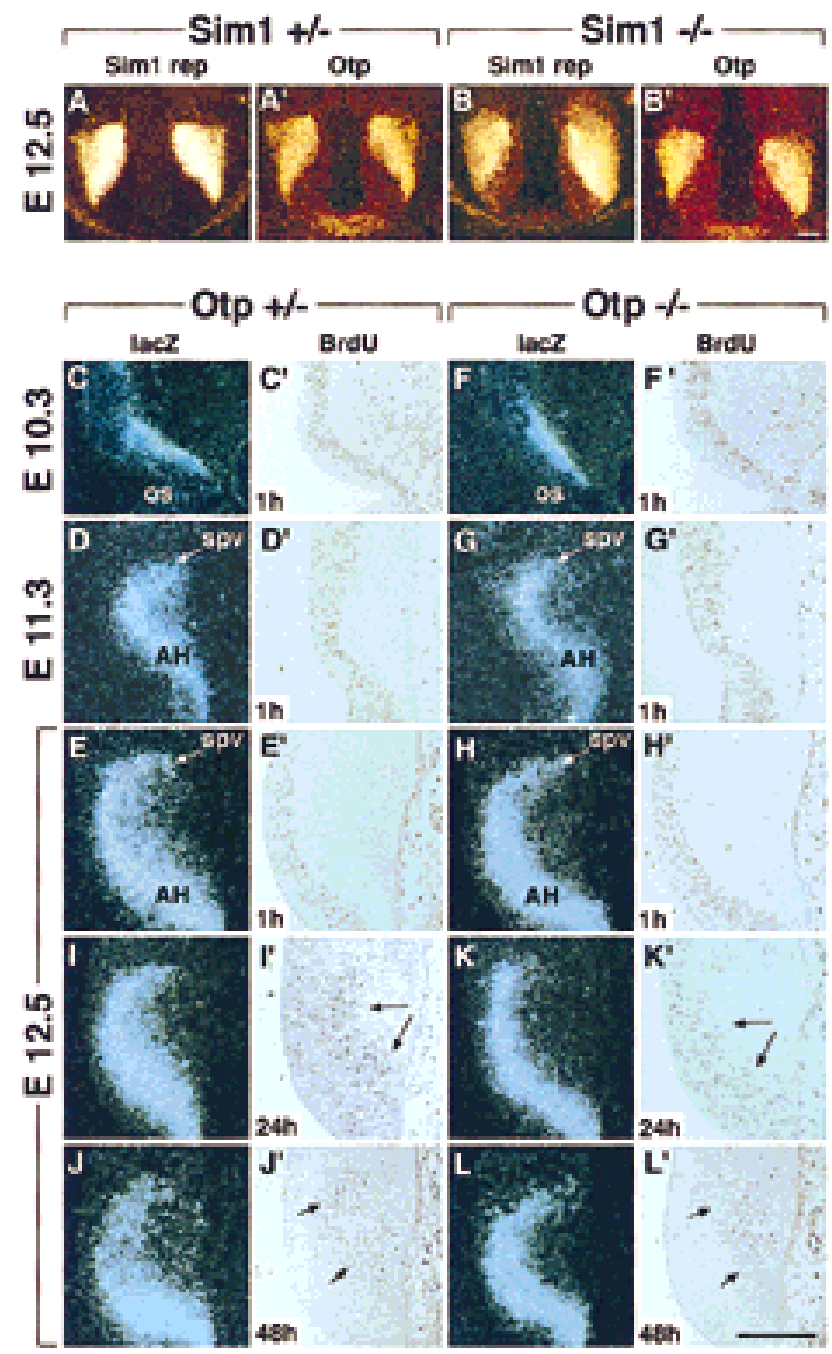

Figure 7. Otp expression in Sim1 $1^{-/-}$mutants and cell proliferation in $O t p^{-/-}$embryos. $\left(A-B^{\prime}\right)$ Otp expression $\left(A^{\prime}, B^{\prime}\right)$ was compared with that of the $\operatorname{Sim} 1$ reporter (Sim1 rep) $(A, B)$ in E12.5 Sim $1^{+/-}\left(A, A^{\prime}\right)$ and $\operatorname{Sim} 1^{-/-}\left(B, B^{\prime}\right)$ embryos, showing no obvious difference between the two genotypes, thus indicating that $\operatorname{Sim} 1$ was not required for Otp expression. $\left(C-H^{\prime}\right) 1 a c Z$ expression $(C-H)$ and BrdU-positive cells $\left(C^{\prime}-H^{\prime}\right)$ labeled $1 \mathrm{hr}$ after the injection were compared in $\mathrm{Otp}^{+/-}$and $O t p^{-/-}$embryos at E10.3 $\left(C, C^{\prime}, F^{\prime} F^{\prime}\right), \mathrm{E} 11.3\left(D, D^{\prime}, G, G^{\prime}\right)$, and E12.5 $\left(E, E^{\prime}, H, H^{\prime}\right)$ showing no obvious difference between the two genotypes. Note that lac $Z$ was expressed in the proliferating neuroepithelium only in the portion close to the mantle zone. $\left(I-L^{\prime}\right)$ At E12.5, comparison between lacZ expression $(I-L)$ and BrdU positive cells $\left(I^{\prime}-L^{\prime}\right)$ detected $24\left(I^{\prime}, K^{\prime}\right)$ and $48 \mathrm{hr}\left(I^{\prime}, L^{\prime}\right)$ after a single injection of BrdU reveals that, as compared with $\operatorname{Otp}^{+/-}\left(I, I^{\prime}, J, I^{\prime}\right)$, in $\operatorname{Otp}^{-1-}\left(K, K^{\prime}, L, L^{\prime}\right)$ embryos, the lacZ expression domain was thinner $(K, L)$ and the number of BrdU-positive cells $\left(K^{\prime}, L^{\prime}\right)$ remarkably reduced. Abbreviations as in the previous figures; (os) optic stalk. Arrows in $I^{\prime}, I^{\prime}, K^{\prime}$, and $L^{\prime}$ point to BrdU-positive cells that are diminished in Otp ${ }^{-/-}$embryos. Scale bars, $50 \mu \mathrm{m}$. Scale bar in $B^{\prime}$ refers to $A-B^{\prime}$ and in $L^{\prime}$ to $C-L^{\prime}$.

the number of BrdU-labeled cells was observed in Otp ${ }^{-/-}$ embryos (Fig. 7, cf. J,J' with L, L'). Therefore, these data indicate that, at least between E10.3 and E12, Otp is required for normal proliferating activity and that a de- creased neuroblast proliferation may contribute to explaining the narrowed domain of lacZ expression.

\section{Patterning abnormalities in mice lacking Otp}

Comparison between the expression patterns of Otp and Dlx1, a murine homolog of the Drosophila Distal-less (DI1) gene (Cohen 1990; Price et al. 1991), has suggested that Otp and Dlx1 might contribute to defining subregionally restricted identities within the hypothalamus (Simeone et al. 1994). In particular, at E12.5, the Otp expression in the spv and $\mathrm{AH}$ was complementary to that of Dlx1 in the poa, ventral thalamus (vt), and suprachiasmatic area (sch) (Bulfone et al. 1993; Simeone et al. 1994; Avantaggiato et al. 1995). No abnormalities in the Dlx1 and lacZ expression patterns were detected at this stage in $\mathrm{Otp}^{-/-}$embryos (data not shown).

Compared with Otp $p^{+-}$at E15.5 and P1, in Otp ${ }^{-/-}$ brains, the lac $Z$ expression disappeared from the presumptive PVN territory (Fig. 8, cf. the black asterisk in $\mathrm{A}, \mathrm{C}, \mathrm{E}, \mathrm{G}$ with the white asterisk in $\left.\mathrm{A}^{\prime}, \mathrm{C}^{\prime}, \mathrm{E}^{\prime}, \mathrm{G}^{\prime}\right)$, in which it was replaced by that of Dlx1 (Fig. 8, cf. the white asterisk in $\mathrm{B}, \mathrm{D}, \mathrm{F}, \mathrm{H}$ with the black asterisk in $\left.\mathrm{B}^{\prime}, \mathrm{D}^{\prime}, \mathrm{F}^{\prime}, \mathrm{H}^{\prime}\right)$.

Therefore, even though the complementary expression between lacZ and Dlx1 expression domains was maintained, the presumptive PVN area showed expression of $D 1 \times 1$, a gene that normally is never transcribed in the PVN.

\section{Discussion}

The neurogenesis of the endocrine hypothalamus is characterized by a sequential series of crucial events including initial commitment to the neuronal fate, neuroblast proliferation, migration of postmitotic neurons to the neuroendocrine nuclei, and terminal differentiation that results in neuropeptide activation and axonal outgrowth. We reported that Otp affects all of these events except the initial commitment to the neuronal fate (Fig. 9A,B).

\section{Otp is required for neuroendocrine terminal differentiation}

Mice lacking the Otp gene die soon after birth and fail in terminal differentiation of neuroendocrine cell types corresponding to parvocellular and magnocellular neurons of the PVN, SON, aPV, and ARN. In particular, TRH, CRH, SS, OT, and AVP neuropeptide transcription and axonal outgrowth fail to be established in $\mathrm{Otp}^{-/-} \mathrm{mu}-$ tants (Fig. 9A). Failure in terminal differentiation of specific neuroendocrine cell lineages has been reported in

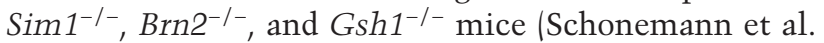
1995; Li et al. 1996; Michaud et al. 1998). In this context, the finding that Otp controls not only aPV, PVN, and SON cell types that require $\operatorname{Sim} 1$ or $\operatorname{Sim} 1$ and Brn2, but also SS-producing neurons of the ARN, provides further support to the concept that specific combinations of 


\section{Otp +/- Otp -/- Otp +/- Otp -/-}
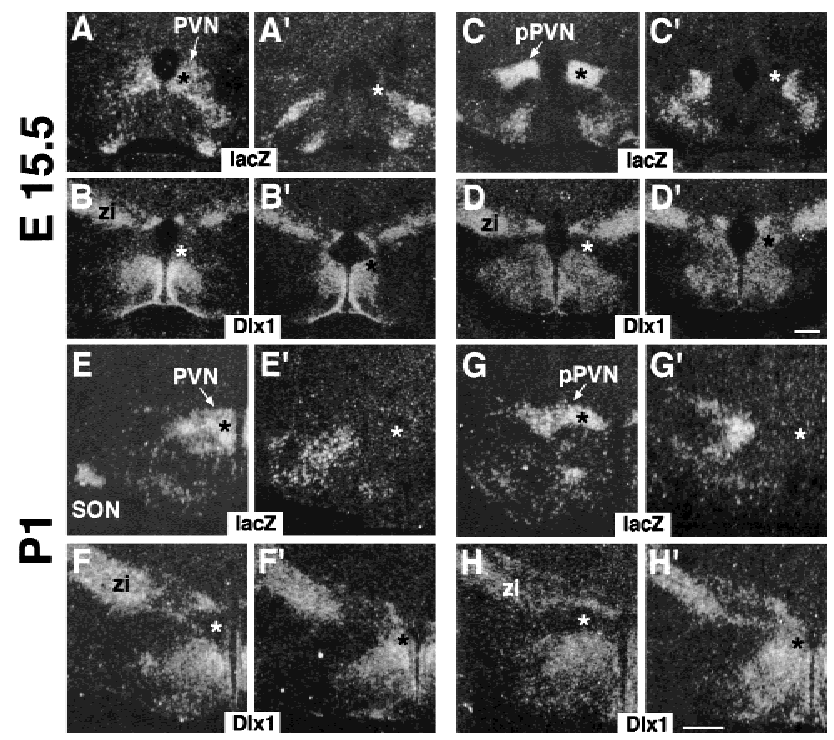

Figure 8. Patterning abnormalities in $\mathrm{Otp}^{-/-}$mutants. $\left(A-H^{\prime}\right)$ Adjacent frontal sections through the hypothalamus of $\mathrm{Otp}^{+/-}$ $(A-H)$ and $O t p^{-/-}\left(A^{\prime}-H^{\prime}\right)$ at E15.5 $\left(A-D^{\prime}\right)$ and P1 $\left(E-H^{\prime}\right)$ hybridized with lacZ and Dlx1 showing that in the PVN of Otp ${ }^{+/-}$ brain, $1 a c Z$ and $D l \times 1$ show complementary expression (cf. black asterisk in $A, C, E, G$ with white asterisk in $B, D, F, H)$, where as in the area corresponding to the presumptive PVN of Otp ${ }^{-/-}$mutants, the lacZ and Dlx1 complementary expression was inverted (cf. white asterisk in $A^{\prime}, C^{\prime}, E^{\prime}, G^{\prime}$ with black asterisk in $\left.B^{\prime}, D^{\prime}, F^{\prime}, H^{\prime}\right)$. Abbreviations as in previous figures; (zi) zona incerta. Scale bars, $50 \mu \mathrm{m}$. Scale bar in $D^{\prime}$ refers to E15.5 and in $H^{\prime}$ to P1 brains.

regulatory factors are necessary to confer differentiative information that underlie the acquisition of a specific cellular identity (Figdor and Stern 1993; Puelles and Rubenstein 1993; Lamoniere et al. 1996; Sharp and Morgan 1996; Sornson et al. 1996; Treier and Rosenfeld 1996). Moreover, we also reported that the ventricular neuroepithelium adjacent to the ME of Otp ${ }^{-/-}$brain is abnormally increased, suggesting that Otp might be required also for processes other than the differentiation of specific neuroendocrine cell lineages.

\section{Cell proliferation, apoptosis and cell migration in Otp mutants}

The first abnormality detected in Otp $\mathrm{p}^{-/-}$embryos corresponds to a narrowed lac $Z$ expression domain due to a reduced number of cells expressing it. This may be caused by either a decreased cell proliferation or increased cell death. Our findings indicate that a diminished proliferating activity of cells that should transcribe Otp is responsible for the lower number of lacZ-expressing cells between E10 and E13. Interestingly, between E10 and E13, lacZ is not expressed through the entire proliferating neuroepithelium, but is excluded from the ventricular side and maintained in the neuroepithelium close to the mantle zone. A detailed comparison of Otp expression and BrdU-positive cells indicates that the number of BrdU-positive cells labeled at E11.3 and identified at E12.5 within the lacZ expression domain results remarkably decreased in Otp ${ }^{-/-}$embryos. Moreover, because the abnormal proliferating activity is not revealed after a BrdU pulse of $1 \mathrm{hr}$, it can be argued that Otp might be required to control the number of cell divisions and/ or the length of the cell cycle only in neuroblasts expressing it. However, because a reduction in the number of lacZ-expressing cells may also be due to an increased cell death, an exhaustive analysis to detect apoptosis has been performed (see Material and Methods section).

No apoptotic cells are detected at any of the stages analyzed, thus indicating that apoptosis does not contribute to the Otp $p^{-/-}$abnormalities. Nevertheless, it cannot be excluded that in Otp ${ }^{-/-}$embryos, cells die for a different reason. In this context, between E13.5 and E14.5, at the level of the poa, lacZ-positive cells of the spv primordium appeared disorganized and then disappeared, leading us to strongly suspect that at least these cells die, even though apoptosis is not revealed. Apoptosis has not been reported in $\mathrm{Sim} 1^{-/-}$or Brn2 ${ }^{-/-}$mutants (Nakai et al. 1995; Schonemann et al. 1995; Michaud et al. 1998), even though it appears not increased in Sim1-1mutants (Michaud J., pers. comm.).

Therefore, although our findings indicate that reduced proliferation is a major abnormality detected in Otp ${ }^{-/-}$ embryos, we favor the possibility that a fraction of lacZexpressing cells die from E13 onward. To follow the fate of Otp-expressing cells, the Otp gene has been replaced with the lac $Z$ reporter gene whose expression was correctly driven by the Otp promoter elements. In Otp $p^{-/-}$ brain at $\mathrm{P} 1$, the lac $Z$ expression domain is heavily affected, as it is abnormal in position and extent. The residual lacZ-positive cells, instead of being localized in the presumptive PVN and SON, occupy a ventro-lateral domain in which they are never found in normal embryos. Abnormal migration of lacZ-expressing cells is also supported by the abnormal position of both calband BrdU-positive cells from E12 onward. Moreover, the finding that $\operatorname{Sim} 1$ and $l a c Z$ are coexpressed also in $O t p^{-/-}$embryos, provides further evidence that lacZ/ Sim1-positive cells identified in abnormal position correspond to those cells that should be normally fated to form the PVN and SON and that, in the absence of Otp, lack this important commitment and fail to properly migrate. This finding suggests that the absence of a single gene function, namely Otp, results in the abnormal positioning of cells normally fated to generate hypothalamic neuroendocrine nuclei and suggests that, in these cells, proper migration and differentiation are controlled by the same gene product. In this context, it should be interesting to analyze cell migration in Sim1 and/or Brn2 mutant mice. Moreover, understanding the abnormalities of Otp ${ }^{-/-}$mutants might help in the future to define, in more detail, genetic requirement(s) conferring positional value to neuronal precursors of restricted cell lineages (see also below).

In summary, Otp plays a role in proliferation and/or 


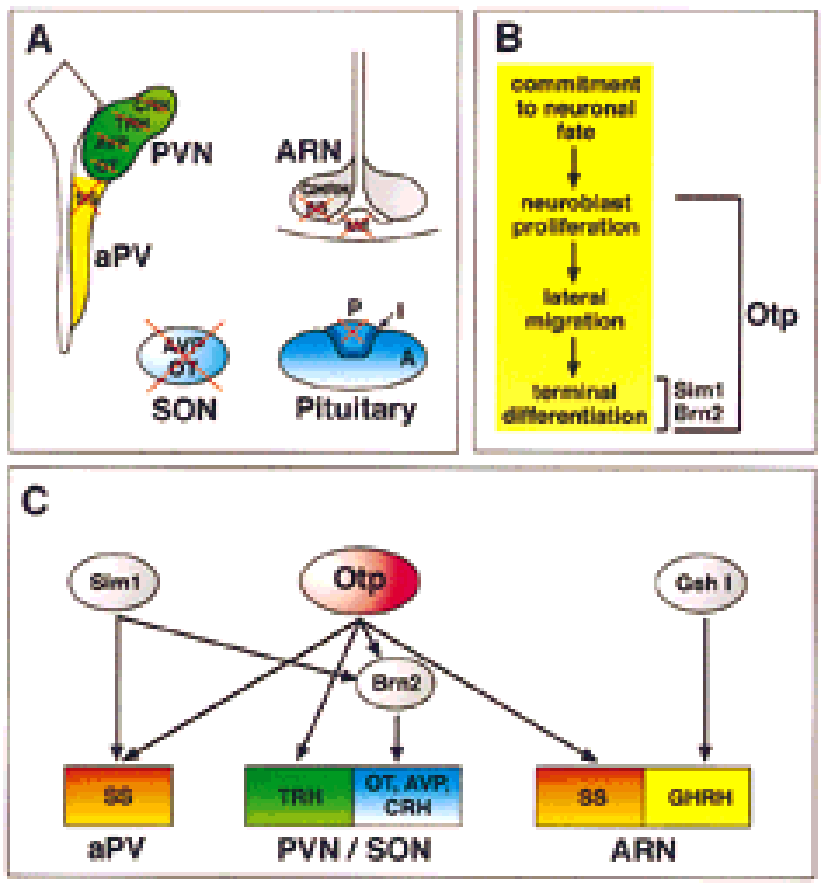

Figure 9. Schematic summary illustrating neuroendocrine impairments, abnormal developmental processes, and genetic interactions deduced from the analysis of $\mathrm{Otp}^{-/-}$mice. (A) In wildtype mice magnocellular and parvocellular neurons of the PVN, SON, aPV, and ARN secrete OT, AVP, CRH, TRH, SS, and GHRH neuropeptides. Magnocellular neurons located in the PVN and SON project their axons to the posterior lobe of the pituitary, whereas parvocellular neurons of the PVN, aPV, and ARN project to the ME. In Otp $p^{-/-}$mice, failure in terminal differentiation results in morphological disruption of PVN and SON, lack of CRH, TRH, AVP, OT, and SS neuropeptides expression, and impaired axonal outgrowth to the ME and posterior pituitary. (B) Developmental milestones of neuroendocrine hypothalamus are represented by the early commitment to the neuronal fate, neuroblast proliferation, lateral migration of postmitotic neurons to the area of nuclei formation, and terminal differentiation including neuropeptide expression, axonal outgrowth, and maintenance of cell viability. In $\mathrm{Brn}^{-/-}$and Sim1 $1^{-/}$mice, terminal differentiation of cell lineages secreting CRH, AVP, OT (for Brn2), and CRH, AVP, OT, TRH, and SS (for Sim1) is disrupted. In Otp $\mathrm{t}^{-/-}$mice, beside the failure in terminal differentiation of $\mathrm{CRH}, \mathrm{AVP}, \mathrm{OT}, \mathrm{TRH}$, and SS cell lineages, there is also an impairment in both neuroblast proliferation, and their subsequent migration, indicating that Otp is an important requirement of most of the crucial steps necessary for proper development of the neuroendocrine hypothalamus. $(C)$ Otp is required from E12 onward for Brn2 and neuropeptide expression. Similar findings have been provided in Sim1-/mice. Our data indicate that Sim1 and Otp are largely coexpressed and that $\operatorname{Sim} 1$ and Otp expression is unaffected in $O t p^{-/-}$and Sim1 $1^{-/-}$embryos, respectively, thus providing genetic evidence that they act in parallel and are both required for Brn2 expression. However, it cannot be argued from our data whether Sim 1 and Otp require an additional genetic element to activate SS and TRH expression in the aPV and PVN, respectively. Finally, in the ARN, Otp is required only for SS but not for GHRH expression that is controlled by Gsh1. These data support the existence of a complex hierarchy of genetic interactions among transcription factors selectively required in specific cell lineages of the developing neuroendocrine hypothalamus. survival as well as migration and differentiation. Multiple requirements might be the consequence of different cell and stage-specific roles, or, alternatively, all the abnormalities identified might be the consequence of an early and unique role that appears first manifested with abnormal proliferation and reduced cell number and later with impaired migration and failure in terminal differentiation. This aspect is potentially of great interest as it raises the question of whether events underlying neuroendocrine development are hierarchically interdependent or independent.

Further experiments on the basis of cell-restricted and stage-specific inactivation of Otp might provide insights into these aspects.

\section{Patterning abnormalities in Otp mutants}

Along the hypothalamus, the Otp-expression domain is complementary to that of Dlx1 (Simeone et al. 1994). This observation has suggested that Otp and Dlx might contribute to defining specific territorial identities by supplying positional and differentiative information within the secondary prosencephalon or the neuromere D1 (Figdor and Stern 1993; Puelles and Rubenstein 1993). Moreover, it has also been proposed that diencephalic neuromeres may represent discrete units of polyclonal cell population with restricted lineages (Figdor and Stern 1993). Precursor cells of a polyclonal population were generated in the neuroepithelium and migrate to reach their final destination. In this context, cell lineage-restricted expression of regulatory genes might represent a crucial step for cells to both migrate to the final destination and restrict their identity.

In the secondary prosencephalon of Otp $p^{-/-}$brain, lacZpositive cells retain Sim1 expression, but abnormally migrate, disappearing from the presumptive PVN area in which, conversely, Dlx1, a gene never expressed in the PVN, is abundantly transcribed, thus suggesting that Dlx1-positive cells have replaced PVN-committed cells (positive for lacZ and Sim1 expression) that have abnormally migrated. Finally, the observation that, although in an abnormal position, the lacZ and Dlx1 domains maintain their complementary expression, indicates that even in the absence of Otp, lacZ and Dlx1-expressing cell populations retain a sufficient degree of specific identity and, thereby, do not mix with each other.

\section{Otp acts upstream of Brn2 and in parallel with Sim1}

Our data on Otp and previous reports on the role of Brn2, Sim1, and Gsh1 (Nakai et al. 1995; Schonemann et al. 1995; Li et al. 1996; Michaud et al. 1998) genes support the idea that different combinations of transcription factors act in concert to specify a developmental program leading to the generation of distinct neuroendocrine cell lineages. Analysis of Brn2 mutant mice revealed that it acts relatively late in neuroendocrine development, being required for terminal differentiation events of $\mathrm{CRH}$, AVP, and OT cell lineages (Fig. 9B,C) (Schonemann et al. 
1995; Sharp and Morgan 1996; Treier and Rosenfeld 1996).

Sim1 mutant mice showed a more general effect, as they were impaired in terminal differentiation events leading to the activation of neuropeptides of the PVN and SON as well as of SS in the aPV (Fig. 9B,C; Michaud et al. 1998). Interestingly, from E12.5 onward, Sim1-1mutants gradually lack Brn2 expression in the dorsal spv primordium indicating that $\operatorname{Sim} 1$ acts upstream of Brn2 and is required for maintenance of its expression (Fig. 9C; Michaud et al. 1998). Our data reveal a striking similarity with $\operatorname{Sim} 1$ mutant phenotype. Except in the ARN, Otp is fully coexpressed in time and space with $\operatorname{Sim} 1$, and is required for both terminal differentiation of parvocellular and magnocellular neurons of aPV, PVN, and SON and for maintenance of Brn2 expression. Noteworthy, at E11.5, Brn2 expression is slightly toned down and, at E12.5, disappears from the entire spv and adjacent territory in which it is coexpressed with Otp, thus suggesting that as compared with $\operatorname{Sim} 1^{-/-}$phenotype, Otp may have a more generalized role in controlling Brn2 expression in post-mitotic neurons and may open the question as to whether Sim1 and Otp act in parallel, or if one is downstream the other in controlling Brn2 expression. Interestingly, in Otp ${ }^{-/-}$embryos, Sim1 expression is maintained in lacZ-positive cells in which Brn2 is lost and, in Sim $1^{-/-}$embryos, Otp is expressed in the territory in which Brn2 disappears. These findings provide strong in vivo evidence that Otp and Sim 1 act in parallel and are both required for proper expression of Brn2 in the spv and its derivatives, the PVN and SON (Fig. 9C).

However, it is yet unclear whether Otp-mediated activation of TRH and SS also requires an additional intermediate transcription factor. We also show that in the ARN of Otp ${ }^{-/-}$brains, SS, but not GHRH, expression is affected. Interestingly, in the ARN, the homeobox-containing gene Gsh1 is essential for GHRH expression (Fig. 9C; Li et al. 1996). Therefore, summing up our data, Otp is required early for proper proliferating activity and, subsequently, for proper migration and terminal differentiation events that involve maintenance of Brn2 expression, activation of parvocellular and magnocellular neuropeptide gene expression, axonal outgrowth, and cell survival (Fig. 9A-C). Finally, as no roles have been described so far for Sim1, Brn2, and Gsh1 in modulating cell proliferation and/or migration of neuroendocrine precursor cells, Otp is the first example of a transcription factor required for controlling multiple developmental milestones that lead to the establishment of the main neuroendocrine cell lineages within the murine hypothalamus.

\section{Materials and methods}

Targeting vector, ES cell transfection, and selection of targeted clones

A 1.0-kb DraI fragment, located 60-bp upstream of the Otp translation start site and a $6.0-\mathrm{kb} E c o \mathrm{RI} / \mathrm{XmnI}$ fragment spanning a region containing the second intron and the third exon, were cloned in the pGN plasmid (Le Mouellic et al. 1990) and flanked the lacZ reporter gene and a neomycin resistance cassette, all in the same orientation. Fifteen micrograms of targeting vector were linearized by $\mathrm{KpnI}$ digestion and electroporated into $2 \times 10^{7} \mathrm{HM}-1 \mathrm{ES}$ cells. A total of 450 clones were analyzed by PCR and 3 homologous recombinants were identified with the following primers: sense primer, $5^{\prime}$-ACTTTGTTGTTGGCTGGCTCTGA-3'; antisense primer, 5' -CAGTCACGACGTTGTAAAACGACG-3' (arrows in Fig. 1A) and confirmed in Southern blot assays by hybridizing ApaI and EcoRI-digested genomic DNA with probes a and c (Fig. 1A).

\section{Mouse production and genotyping}

Two independent positive clones were injected into C57BL/6 blastocysts and the resulting chimaeric males back-crossed to B6/D2 F1 females. Genotyping was performed by PCR with two primers specific for the wild-type allele and located in the Otpdeleted sequence (sense primer, 5'-GAAAGATGCCGCCGAGCTTCTG-3'; antisense primer, 5' -TGTCTGGGTCTTTGGCGTCAC-3') (open arrowheads in Fig. 1A) and two primers specific for the lacZ gene (Acampora et al. 1995; filled arrowheads in Fig. 1A).

\section{Western blot analysis}

Total extracts were prepared from E13.5 embryos. A total of 80 $\mu \mathrm{g}$ of these extracts and $10 \mu \mathrm{g}$ of nuclear extracts of HeLa cells transfected with plasmids overexpressing human Otp cDNA under a CMV enhancer-promoter (Simeone et al. 1994) were electrophoresed and transferred to nitrocellulose in a standard Western blot assay, probed with an affinity purified $\alpha \mathrm{OTP}$ antiserum (Lin et al. 1999) (dilution 1:1000) and revealed by the standard Alkaline Phosphatase method.

\section{$\beta$-Gal staining}

Embryos were fixed in $4 \%$ paraformaldehyde for $15 \mathrm{~min}$, followed by two washes with PBS for $10 \mathrm{~min}$ at room temperature. Staining was carried out overnight at $37^{\circ} \mathrm{C}$ in PBS containing 5 $\mathrm{mm} \mathrm{K}_{4} \mathrm{Fe}(\mathrm{CN})_{6}, 5 \mathrm{~mm} \mathrm{~K}_{3} \mathrm{Fe}(\mathrm{CN})_{6}, 2 \mathrm{~mm} \mathrm{MgCl}_{2}, 20 \mathrm{~mm}$ Tris (pH $8)$, and $1 \mathrm{mg} / \mathrm{ml} \mathrm{X-Gal}$.

\section{Histology and staining for calb-D28K}

For histology, P1 brains and embryos were fixed in $4 \%$ paraformaldehyde for $16 \mathrm{hr}$, processed for wax embedding, sectioned at $7 \mu \mathrm{m}$ and stained with Cresyl violet (brain). Calb-positive cells were revealed on brain and embryo sections by use of an anti-calb-D28K antibody (SWant) according to the manifacturer's instructions.

\section{In situ hybridization}

In situ hybridization experiments were performed as described (Simeone 1998). The Dlx1 probe was the same as described previously (Simeone et al. 1994). The Otp and lacZ probes corresponded to probe $\mathrm{b}$ and $\mathrm{c}$ in Figure 1A. Probe b was a 500-bp long fragment spanning the Otp exon II; probe c is a 800-bp long fragment of the lacZ gene. Sim1 and Brn2 were two RT-PCRamplified fragments spanning the region between amino acids 534 and 758 (for Sim1) and between amino acids 151 and 287 (for Brn2). The Sim1 reporter (Sim1 rep) probe used in $\operatorname{Sim}^{-1-}$ mutants was the same as described previously (Michaud et al. 1998). 


\section{BrdU labeling and detection of apoptotic cells}

Pregnant mice at E10.3, E11.3, and E12.3 were injected intraperitoneally with BrdU solution $(50 \mathrm{mg} / \mathrm{kg}$ body weight) and sacrificed after $1 \mathrm{hr}$, or at E12.5 and P1 (for mice injected at E10.3 and E11.3). Four embryos for each genotype for each BrdU administration were analyzed. Wax-embedded embryos were sectioned and adjacent sections were processed for BrdU detection or in situ hybridization. BrdU detection was performed according to Xuan et al. (1995).

To detect apoptotic cells, embryo sections were processed according to the TUNEL method (Garvieli et al. 1992). Four embryos were analyzed at E10.3, 11.3, 12.3, 14.5, and 15.5, and four brains at P1. Pregnant mice of two of the four embryos analyzed at E10.3, 11.3, and 12.3 were also injected with BrdU and processed in parallel for detection of both apoptotic and BrdU-positive cells.

\section{Acknowledgments}

We thank M. Terracciano for technical support and A. Secondulfo for manuscript preparation. J.M. thanks T. Lufkin for the Otp probe. This work was supported by the Italian Telethon Program, the Italian Association for Cancer Research (AIRC), the CNR Target Project on Biotechnology, the Ministero dell' Universitá e della Ricerca Scientifica e Tecnologica (MURST)CNR Biotechnology Programme Legge 95/95 and the EU Biotech program. J.M. was supported by an operating grant from the Medical Research Council of Canada and F.M.V. by the Korczak Foundation.

The publication costs of this article were defrayed in part by payment of page charges. This article must therefore be hereby marked "advertisement" in accordance with 18 USC section 1734 solely to indicate this fact.

\section{References}

Acampora, D., S. Mazan, F. Tuorto, V. Avantaggiato, J.J. Tremblay, D. Lazzaro, A. di Carlo, A. Mariano, P.E. Macchia, G. Corte et al. 1998. Transient dwarfism and hypogonadism in mice lacking Otx1 reveal prepubescent stage-specific control of pituitary levels of GH, FSH and LH. Development 125: 1229-1239.

Alvarez-Bolado, G., M.G. Rosenfeld, and L.W Swanson. 1995. Model of forebrain regionalization based on spatiotemporal patterns of POU-III homeobox gene expression, birthdates, and morphological features. J. Comp. Neurol. 355: 237-295.

Avantaggiato, V., P.P. Pandolfi, M. Ruthardt, N. Hawe, D. Acampora, P.G. Pelicci, and A. Simeone. 1995. Developmental analysis of the murine Promyelocyte Leukaemia Zinc Finger $(P L Z F)$ gene expression: Implications for the neuromeric model of the forebrain organization. I. Neurosci. 15: 4927-4942.

Bach, I., S.J., Rhodes, R.V. Pearse II, T. Heinzel, B. Gloss, K.M. Scully, P.E. Sawchenko, and M.G. Rosenfeld. 1995. P-Lim, a LIM homeodomain factor, is expressed during pituitary organ and cell commitment and synergizes with Pit-1. Proc. Nat1. Acad. Sci. 92: 2720-2724.

Bach, I., C. Carrière, H.P. Ostendorff, B. Andersen, and M.G. Rosenfeld. 1997. A family of LIM domain-associated cofactors confer transcriptional synergism between LIM and Otx homeodomain proteins. Genes \& Dev. 11: 1370-1380.

Bodner, M., J.L. Castrillo, L.E. Theill, T. Deerinck, M. Ellisman, and M. Karin. 1988. The pituitary-specific transcription factor GHF-1 is a homeobox-containing protein. Cell 55: 505518.
Bulfone, A., L. Puelles, M.H. Porteus, M.A. Frohman, G.R. Martin, and J.L.R. Rubenstein. 1993. Spatially restricted expression of Dlx-1, Dlx-2 (Tes-1), Gbx-2, and Wnt-3 in the embryonic day 12.5 mouse forebrain defines potential transverse and longitudinal segmental boundaries. I. Neurosci. 13: $3155-3172$.

Cohen, S.M. 1990. Specification of limb development in the Drosophila embryo by positional cues from segmentation genes. Nature 343: 173-177.

Enderlin, S., A.W. Norman, and M.R. Celio. 1987. Ontogeny of the calcium binding protein calbindin $\mathrm{D}-28 \mathrm{~K}$ in the rat nervous system. Anat. Embryol. 177: 15-28.

Felig, P., J.D. Baxter, A.E. Brodaus, and L.A. Frohman. 1987. In Endocrinology and metabolism McGraw-Hill, New York, NY.

Figdor, M.C. and C.D. Stern. 1993. Segmental organization of embryonic diencephalon. Nature 363: 630-634.

Gass, G.H. and H.M. Kaplan. 1996. In Handbook of endocrinology. 2nd ed. CRC Press, Inc, Boca Raton, FL.

Gavrieli, Y., Y. Sherman, and S.A. Ben-Sasson. 1992. Identification of programmed cell death in situ via specific labeling of nuclear DNA fragmentation. J. Cell Biol. 119: 493-501.

He, X., A. Treacy, M.N. Simmons, D.M. Ingraham, H.A. Swanson, and M.G. Rosenfeld. 1989. Expression of a large family of POU-domain regulatory genes in mammalian brain development. Nature 340: 35-41.

Ingraham, H.A., R.P. Chen, H.J. Mangalam, H.P. Elsholtz, S.E. Flynn, Lin, C.R., D.M. Simmons, L. Swanson, and M.G. Rosenfeld. 1988. A tissue-specific transcription factor containing a homeobox specifies a pituitary phenotype. Cell 55: 519-529.

Karim, M.A. and J.C. Sloper. 1980. Histogenesis of the supraoptic and paraventricular neurosecretory cells of the mouse hypothalamus. J. Anat. 130: 341-347.

Lamoniere, T., J.J. Tremblay, C. Lanctôt, M. Therrien, Y. Gauthier, and J. Drouin. 1996. Ptx1, a bicoid-related homeo box transcription factor involved in transcription of the proopiomelanocortin gene. Genes \& Dev. 10: 1284-1294.

Le Mouellic, H., Y. Lallemand, and P. Brûlet. 1990. Targeted replacement of the homeobox gene Hox-3.1 by the Escherichia coli lacZ in mouse chimeric embryos. Proc. Natl. Acad. Sci. 87: 4712-4716.

Li, H., P.S. Zeitler, M.T. Valerius, K. Small, and S.S. Potter. 1996. Gsh-1, an orphan Hox gene, is required for normal pituitary development. EMBO J. 15: 714-724.

Li, S., E.B. Crenshaw, E.J. Rawson, D.M. Simmons, L.W. Swanson, and M.G. Rosenfeld. 1990. Dwarf locus mutants lacking three pituitary cell types result from mutations in the POUdomain gene pit-1. Nature 347: 528-533.

Lin, X., M.W. State, F.M. Vaccarino, J. Greally, M. Hass, and J.F. Leckman. 1999. Identification, chromosomal assignment, and expression analysis of the human homeodomain-containing gene Orthopedia (OTP). Genomics 60: 96-104.

Michaud, J.L., T. Rosenquist, N.R. May, and C.-M. Fan. 1998. Development of neuroendocrine lineages requires the bHLH-PAS transcription factor SIM1. Genes \& Dev. 12: 3264-3275.

Nakai, S., H. Kawano, T. Yudate, M. Nishi, J. Kuno, A. Nagata, K. Jishage, H. Hamada, H. Fujii, K. Kawamura, K. Shiba, and T. Noda. 1995. The POU domain transcription factor Brn-2 is required for the determination of specific neuronal lineages in the hypothalamus of the mouse. Genes \& Dev. 9: 3109-3121.

Price, M., M. Lemaistre, M. Pischetola, R. Di Lauro, and D. Duboule. 1991. A mouse gene related to distal-less shows a restricted expression in the developing forebrain. Nature 
351: 748-751.

Puelles, L. and J.L.R. Rubenstein. 1993. Expression patterns of homeobox and other putative regulatory genes in the embryonic mouse forebrain suggest a neuromeric organization. Trends Neurosci. 16: 472-479.

Rubenstein, J.L.R., S. Martinez, K. Shimamura, and L. Puelles. 1994. The embryonic vertebrate forebrain: The prosomeric model. Science 266: 578-580.

Schonemann, M.D., A.K. Ryan, R.J. McEvilly, S.M. O'Connell, C.A. Arias, K.A. Kalla, P. Li, P.E. Sawchenko, and M.G. Rosenfeld. 1995. Development and survival of the endocrine hypothalamus and posterior pituitary gland requires the neuronal POU domain factor Brn-2. Genes \& Dev. 9: 3122 3135.

Sharp, D.Z. and W.W. Morgan. 1996. Brain POU-er. BioEssays 18: $347-350$.

Sheng, H.Z., A.B. Zhadanov, B. Mosinger, Jr., T. Fujii, S. Bertuzzi, A. Grinberg, E.J. Lee, S.-P. Huang, K.A. Mahon, and H. Westphal. 1996. Specification of pituitary cell lineages by the LIM homeobox gene Lhx3. Science 272: 1004-1007.

Simeone, A. 1998. Detection of mRNA in tissue sections with radiolabelled riboprobes. In In situ hybridization. A practical approach (ed. D.G. Wilkinson), 2nd ed., pp 69-86. Oxford University Press, Oxford UK.

Simeone, A., M.R. D'Apice, V. Nigro, J. Casanova, F. Graziani, D. Acampora, and V. Avantaggiato. 1994. Orthopedia, a novel homeobox-containing gene expressed in the developing central nervous system of both mouse and Drosophila. Neuron 13: 83-101.

Simmons, D.M., J.W. Voss, H.A. Ingraham, J.M. Halloway, R.S. Broide, M.G. Rosenfeld, and L.W. Swanson. 1990. Pituitary cell phenotypes involve cell-specific Pit-1 mRNA translation and synergistic interactions with other classes of transcription factors. Genes \& Dev. 4: 695-711.

Sornson, M.W., W. Wu, J.S. Dasen, S.E. Flynn, D.J. Norman, S.M. O'Connell, I. Gukovsky, C. Carrière, A.K. Ryan, A.P. Miller et al. 1996. Pituitary lineage determination by the Prophet of Pit-1 homeodomain factor defective in Ames dwarfism. Nature 384: 327-333.

Swanson, L.W. 1986. Organization of mammalian neuroendocrine system. In Handbook of physiology. Sec. 1, The nervous system, Vol. IV, Intrinsic regulatory systems of the brain (ed. V.B. Mountcastle, Floyd E. Bloom, and S.R. Geinger), pp. 317-363. American Physiological Society, Bethesda, MD.

- 1987. The hypothalamus. In Handbook of chemical neuroanatomy, Part I (ed. A. Bjorklun, T. Hokfelt, and L.W. Swanson), pp. 1-124. Elsevier Publishing Company, Amsterdam, The Netherlands.

Szeto, D.P., A.K. Ryan, S.M. O'Connell, and M.G. Rosenfeld. 1996. P-OTX: A Pit-1 interacting homeodomain factor expressed during anterior pituitary gland development. Proc. Nat1. Acad. Sci. 93: 7706-7710.

Treier, M. and M.G. Rosenfeld. 1996. The hypothalamic-pituitary axis: Co-development of two organs. Curr. Opin. Cell Biol. 8: 833-843.

Wilson, J.D. and D.W. Foster. 1992. In Williams textbook of endocrinology. 8th ed., W.B. Saunders Company, Philadelphia, PA.

Xuan, S., C.A. Baptista, G. Balas, W. Tao, V.C. Soares, and E. Lai. 1995. Winged helix transcription factor BF-1 is essential for the development of the cerebral hemispheres. Neuron 14: 1141-1152. 


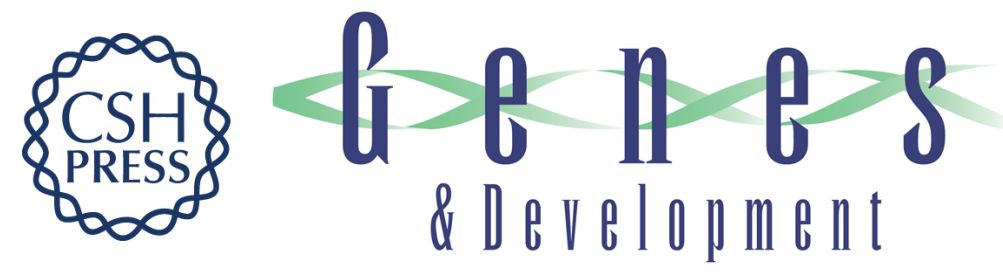

\section{Progressive impairment of developing neuroendocrine cell lineages in the hypothalamus of mice lacking the Orthopedia gene}

Dario Acampora, Maria Pia Postiglione, Virginia Avantaggiato, et al.

Genes Dev. 1999, 13:

References This article cites 33 articles, 15 of which can be accessed free at:

http://genesdev.cshlp.org/content/13/21/2787.full.html\#ref-list-1

License

Email Alerting

Receive free email alerts when new articles cite this article - sign up in the box at the top

Service

right corner of the article or click here.

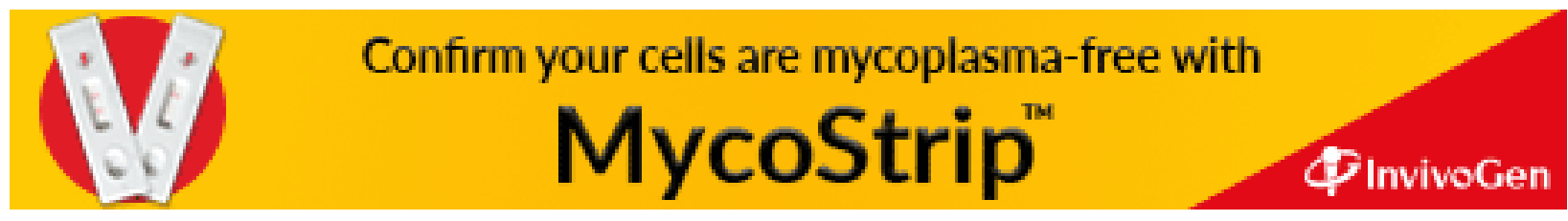

